Illinois State University

ISU ReD: Research and eData

Theses and Dissertations

$10-2-2016$

\title{
The Impact of Gender-Biased Language in State Regulations Upon Judgments About Foster Children
}

Hannah R. J. Heinzel

Illinois State University, hannahrosejones1@gmail.com

Follow this and additional works at: https://ir.library.illinoisstate.edu/etd

Part of the Social Psychology Commons

\section{Recommended Citation}

Heinzel, Hannah R. J., "The Impact of Gender-Biased Language in State Regulations Upon Judgments About Foster Children" (2016). Theses and Dissertations. 617.

https://ir.library.illinoisstate.edu/etd/617

This Thesis is brought to you for free and open access by ISU ReD: Research and eData. It has been accepted for inclusion in Theses and Dissertations by an authorized administrator of ISU ReD: Research and eData. For more information, please contact ISUReD@ilstu.edu. 


\title{
THE IMPACT OF GENDER-BIASED LANGUAGE IN STATE REGULATIONS UPON JUDGMENTS ABOUT FOSTER CHILDREN
}

\author{
Hannah R. J. Heinzel
}

93 Pages

This study investigated the impact of gender-biased language in the wording of state regulations governing the treatment of foster children in Illinois. Participants were given excerpts of legal language written with either gender-biased or gender-inclusive language and then asked to judge a hypothetical situation involving a male or a female child. It was hypothesized that gender-biased language would have differential effects on interpretation of the language for boys versus girls; we also proposed a moderated mediation model that hypothesized activation of gendered constructs would mediate the interpretation of gendered language. According to the hypothesized model, participant sexism and attitudes towards gender-biased language would moderate these relationships. Analyses were conducted using data collected from 274 participants using an online survey on Amazon's Mechanical Turk. Analyses did not support our main hypotheses; language type and gender of child did not significantly affect participant evaluations of the hypothetical scenario, and the hypothesized moderated mediation model was not supported. Possible explanations for these findings and future directions are discussed. KEYWORDS: Gender, Language, Gender-biased language, Sexism, Foster care 
THE IMPACT OF GENDER-BIASED LANGUAGE IN STATE REGULATIONS UPON

JUDGMENTS ABOUT FOSTER CHILDREN

HANNAH R. J. HEINZEL

A Thesis Submitted in Partial

Fulfillment of the Requirements

for the Degree of

MASTER OF SCIENCE

Department of Psychology

ILLINOIS STATE UNIVERSITY

2016 
(C) 2016 Hannah R. J. Heinzel 
THE IMPACT OF GENDER-BIASED LANGUAGE IN STATE REGULATIONS UPON JUDGMENTS ABOUT FOSTER CHILDREN

HANNAH R. J. HEINZEL

COMMITTEE MEMBERS:

John B. Pryor, Chair

Eric Wesselmann 


\section{ACKNOWLEDGMENTS}

First, I would like to thank my committee members for their guidance throughout this process. Thanks to Dr. Pryor and Dr. Wesselmann for their constant availability, flexibility, encouragement, and mentorship as I completed this project. Thanks also to Dr. Puri for your feedback.

I would also like to thank the professors at Illinois State University for their knowledge, patience, and humor as I completed my degree program. Thank you for helping to shape me as a researcher and a professional, all while encouraging my love of learning.

Thanks to my parents and family for their unwavering support, to my peers at ISU for helping create a fun and collaborative learning environment, and to the staff and management at the Center for Youth and Family Solutions for encouraging me and cheering me on (and helping make sure the on-call phone got covered).

Finally, a huge thank you to my husband: for love, for support, for jokes, for neverending pep talks, and for pancake study breaks. All of my love.

H. R. J. H. 


\section{CONTENTS}

Page

ACKNOWLEDGMENTS

CONTENTS

TABLES

FIGURES

CHAPTER I: INTRODUCTION 1

CHAPTER II: REVIEW OF RELEVANT LITERATURE 3

$\begin{array}{ll}\text { Language and Cognition } & 3\end{array}$

Categories of Language $\quad 4$

$\begin{array}{ll}\text { Asymmetry as Bias } & 6\end{array}$

Are Masculine Generics Harmful? $\quad 8$

Effects of Masculine Generics: Cognition and Imagery

Effects of Masculine Generics: Judgments and Behavior $\quad 11$

Why Do These Effects Exist? 12

Learning and Reinforcement $\quad 12$

$\begin{array}{ll}\text { Priming Effects } & 13\end{array}$

Individual Difference Variables in Language Interpretation 15

$\begin{array}{ll}\text { Alternative Solutions to Masculine Generics } & 16\end{array}$

A Special Case of Masculine Generics: Foster Care in Illinois 19

$\begin{array}{ll}\text { Overview of Current Study } & 22\end{array}$

$\begin{array}{ll}\text { Hypotheses } & 24\end{array}$

$\begin{array}{ll}\text { CHAPTER III: METHOD } & 28\end{array}$ 
$\begin{array}{ll}\text { Participants } & 28\end{array}$

$\begin{array}{ll}\text { Design and Procedure } & 29\end{array}$

$\begin{array}{ll}\text { Measures } & 31\end{array}$

Open-Ended Response $\quad 31$

Indication of Aggression $\quad 32$

Perceived Applicability of the Licensing Standards 32

$\begin{array}{ll}\text { Evaluation of the Scenario } & 32\end{array}$

Attitudes Towards Sexist/Nonsexist Language 33

Modern Sexism Scale 33

$\begin{array}{ll}\text { Demographics } & 34\end{array}$

CHAPTER IV: RESULTS

$\begin{array}{ll}\text { Open-Ended Responses } & 35\end{array}$

$\begin{array}{ll}\text { Descriptive Statistics } & 35\end{array}$

Effect of Condition on Perceived Applicability of Licensing Standards 38

Effect of Condition on Determination of Guilt 39

Effect of Condition on Determination of Corrective Action 39

Moderated Mediation Analysis: Gender of Child as a Priming Effect 40

$\begin{array}{ll}\text { Exploratory Analyses } & 47\end{array}$

$\begin{array}{ll}\text { CHAPTER V: DISCUSSION } & 48\end{array}$

$\begin{array}{ll}\text { Overview of Findings } & 48\end{array}$

$\begin{array}{ll}\text { Potential Design Issues } & 50\end{array}$

$\begin{array}{ll}\text { Theoretical Issues } & 51\end{array}$

Other Methodological Issues $\quad 52$ 
$\begin{array}{ll}\text { Conclusion } & 54\end{array}$

$\begin{array}{ll}\text { References } & 56\end{array}$

Appendix A: SURVEY MATERIALS 65

Appendix B: INFORMED CONSENT AND DEBRIEFING INFORMATION 89 


\section{TABLES}

Table

Page

1. Descriptive Results and Correlations Among Perceived

Aggression, Applicability of Licensing Standards, Determination

of Guilt, and Corrective Plan

2. Cross-Classifications Between Participant Condition and Determination of Foster Parent Guilt

3. Model Coefficients for the Conditional Process Model in Figure 2

4. Model Coefficients for the Conditional Process Model in Figure 4 


\section{FIGURES}

Figure $\quad$ Page

1. Proposed Moderated Mediation Model Using Modern Sexism as a Moderator 41

2. Statistical Representation of Figure 1 with Unstandardized Regression Paths Denoted

3. Proposed Moderated Mediation Model Using Attitudes Towards Sexist/Nonsexist Language as a Moderator

4. Statistical Representation of Figure 3 with Unstandardized

Regression Paths Denoted 


\section{CHAPTER I: INTRODUCTION}

Language - one of the primary modes of human communication - is an extremely valuable tool. Language allows us to externalize mental processes, including thoughts and feelings, and by putting those mental processes into words, we can cooperate in unprecedented ways. However, evidence suggests that the relationship between language and mental processes may be more complex and even reciprocal; namely, language may play a causal role in shaping our thoughts and mental imagery. This relationship may have detrimental effects when language is used to transmit bias and stereotypes, especially through formal language that may have concrete effects on the treatment of individuals. One such manifestation of formal language that may be affected by the transmission of bias is legal language. This study proposes to evaluate the effects of bias in legal language in one specific context: the treatment of foster children.

In this thesis, I begin by discussing the relationship between language and cognition and provide an overview of the various theories that seek to conceptualize this relationship. I discuss a theoretical approach that seeks to categorize different languages based on their various approaches to grammatical gender. I then provide an overview of different types of gender bias in language and discuss the various ways in which gender bias and sexism are transmitted through grammatical structure.

Next, I explore the various perspectives of research literature that demonstrate the detrimental effects of gender bias in language, followed by a discussion of the proposed underlying mechanisms driving individual response to gender-biased language. Neutralization and feminization are presented as proposed language reforms, but the problem persists in the use of gender-biased language in the foster care system in Illinois. I hypothesize, based on previous literature, that gender-biased language use in the foster care system in Illinois leads to 
differential interpretation of the legal language for boys and girls in foster care. I also propose a moderated mediation model to explain individual reactions to gender-biased language. I then provide transition to an overview of the current study, including methodology and analyses, before a final discussion of findings. 


\section{CHAPTER II: REVIEW OF RELEVANT LITERATURE}

\section{Language and Cognition}

There are several influential theories that seek to conceptualize the relationship between language and thought. The Sapir-Whorf hypothesis (Gentner \& Goldin-Meadow, 2003;

Hamilton, 1988; Hussein, 2012; Martyna, 1980) states that “(1) languages vary in their semantic partitioning of the world; (2) the structure of one's language influences the manner in which one perceives and understands the world; (3) therefore, speakers of different languages will perceive the world differently" (Gentner \& Goldin-Meadow, 2003, p. 4). This hard line of linguistic determinism claims that one's language has a specific structure that influences individual worldviews by creating actual cognitive differences based on one's language of use (Martyna, 1980). A related but more moderate theory is linguistic relativism, wherein theorists argue that language is not strictly deterministic and does not shape cognitive differences, but does reflect our culture and helps preserve and reinforce historically maintained social structures (Hussein, 2012; Parks \& Roberton, 2004; Wasserman \& Weseley, 2009). Other more moderate theories include the Linguistic Category Model, which states that language and cognition are constantly interacting and therefore continually shaping each other (Semin \& Fiedler, 1992; Wigboldus \& Douglas, 2007), and other interpretations of the Linguistic Category Model, such as Maass's (1999) argument that preexisting stereotypes help produce biased language, which then in turn reinforces their transmission and maintenance. Although these theories vary in scope, the general consensus reflects an important interplay between cognition and language. This interplay has important consequences for biases and stereotypes and how they are activated within interpersonal interactions. Ongoing empirical testing has suggested that the interaction between 
language and cognition is an important one that has causal effects on culture and interpersonal relationships (Boroditsky, 2009).

\section{Categories of Language}

These theories hold particular relevance for those interested in the relationship between language and gender, for not all languages treat gender identically. Specifically, world languages can be divided into one of three categories based on their grammatical treatment of gender (Hellinger \& Bußmann, 2001; Stahlberg, Braun, Irmen, \& Sczesny, 2007). In grammatical gendered languages (including Germanic and Romance languages such as German, French, Spanish, and Italian), every noun has a gendered demarcation, even inanimate objects (e.g., in Spanish, the word "boat" is el barco, indicating this noun is masculine). In this way, gender is a function of the language that is constantly made salient. In natural gender languages (such as English), nouns are not grammatically marked such that discussion of gender can often be avoided, especially for inanimate objects (e.g., the boat). However, personal pronouns (i.e., he, she) do serve to demarcate gender, and gender-neutral discussions can be difficult when talking about individual persons. In the last category, genderless languages (such as Turkish) do not use gendered nouns or personal pronouns, making gender an easier topic to avoid. However, it should be noted that gender can be expressly made salient if desired through specifically describing individuals as male or female, and it is often the cultural norm to do so whenever possible (Stahlberg et al., 2007).

Each language type employs different methods of implementing gender in a grammatical context. Stahlberg and colleagues (2007) argue that these differing methods represent a culture's "gender belief system" (p. 163) that is shaped and reinforced by continued use of the language. It

has been argued that these differences have implications for how speakers of different languages 
view gender and use it for cognitive and social cues. There is even evidence to suggest that the use of grammatical gender in language affects the meaning of different words (Boroditsky, Schmidt, \& Phillips, 2003). For example, Wasserman and Weseley (2009) argued that sexist attitudes are specifically promoted in languages with grammatical gender, which has a specific negative impact on females. In a series of three studies, Wasserman and Weseley sampled from students who were either bilingual or native English speakers in advanced language courses. Students were randomly assigned to read a neutral passage in English (a natural gender language) or either French or Spanish, depending on their proficiency (both grammatical gendered languages). After reading the passage, students completed a survey of sexist attitudes in that same language. The researchers found that simply reading in a grammatically gendered language affected sexist attitudes, with those assigned to the tasks in French or Spanish espousing significantly higher sexist attitudes than those assigned to complete the tasks in English. This study allowed the researchers to control for cultural differences, as all participants were from the same country, while testing for the simple effect of type of language use on interpretations of gender. The authors suggested that the reading task may have primed those in the grammatical gendered condition to espouse more sexist attitudes, as gendered language "imply [sic] that men and women represent two different classes in society and that simply making such a distinction suggests that women are inferior" (p. 637). In another compelling example, Prewitt-Freilino, Caswell, and Laakso (2012) performed a cross-cultural analysis and found differing levels of gender equality based on the type of language spoken in a country (i.e., grammatical gendered, natural gendered, or genderless). These effects held when controlling for economic development, geographical location, political climate, religious tradition, and other covariates. 


\section{Asymmetry as Bias}

Although it is tempting to conclude that simply having gender as a linguistic structure is sexist, many argue that the true issue is whether men and women are treated equally by the use of the language (Stahlberg et al., 2007). In natural gender languages, unequal use of the language is highlighted by the presence of asymmetry in the linguistic treatment of men and women. Specifically, there are four types of asymmetrical treatment that can be found in English:

1. Salience of Female Representation. One form of asymmetry can be found when references to females are more complex and therefore more salient (e.g., a female actor is often referred to as an actress). This discrepancy specifically sets women apart, with the male referent serving as the standard and the female referent indicating a discrepancy. This reinforces the idea that the standard person is male and anything else must be denoted. This form of group designation has been shown to prompt the activation of gender stereotypes (Formanowicz, Bedynska, Cislak, Braun, \& Sczesny, 2013). Coined as the People=Male hypothesis (Silveira, 1980; Stahlberg et al., 2007), this type of asymmetry has been found across cultures (Eagly \& Kite, 1987).

2. Gaps in vocabulary. A second form of asymmetry can be found when vocabularies used to describe men and women are not symmetrical. One manifestation of this is when there is a term for one gender but no equivalent term for the other. For example, historical references that refer to virgins are often implied to specifically mean women, while there is not a term for a man who has not yet had sexual intercourse. Similarly, to be a family man is something that men in the United States are encouraged to aspire to, while there is not an equivalent term for women because there is a cultural expectation for women to be primarily devoted to family life. These 
gaps in vocabulary often reflect a historical unequal treatment of the sexes or an unequal distribution of duties and labor (Sendén, Sikström, \& Lindholm, 2015; Stahlberg et al., 2007).

3. Asymmetric word pairs. Related to gaps in vocabulary are asymmetric word pairs, where there are words in the vocabulary to describe both men and women but the female version has a sexual meaning or reflects minority status. For example, an individual described as a governor is viewed as someone with control or authority over others, while a governess is a woman who serves in the role of a nurse, teacher, or babysitter. Another notable example is the master/mistress dichotomy, with a master being viewed as someone who has control over individuals or property. In contrast, a mistress can either be the female counterpart of a master or a woman who engages in extramarital relations - and the latter definition is predominantly used in modern society (Stahlberg et al., 2007).

4. Masculine generics. The final form of asymmetry in natural gender languages is the use of masculine generics. A masculine generic is a word that can be used specifically to refer to males or to mixed-gender groups of both men and women. Examples include the term "mankind" to describe humans, "policeman" to describe a person who works in law enforcement, and the seemingly generic sentence, "If a student wishes to do well in school, he must study hard" (Miller \& James, 2009). In contrast, the female version cannot be used for mixed groups. Researchers argue that this distinction effectively serves to reinforce the idea of the standard human being male (Wasserman \& Weseley, 2009), therefore marginalizing women and girls and equating "maleness with humanness" (Stahlberg et al., 2007, p. 169). This form of 
asymmetry has been perhaps the most widely critiqued and studied within psychological research.

\section{Are Masculine Generics Harmful?}

Masculine generics have been in use in English for over 250 years (MacKay, 1980) and have been critiqued for over a century as being sexist and detrimental to society. The critiques of masculine generics have varied widely in breadth and severity. Elizabeth Cady Stanton, an early champion of women's rights, critiqued masculine generics as vehicles that lead to oppression at worst and misunderstandings at best (Moulton, Robinson, \& Elias, 1978). Similarly, Khan and Daneman (2011) argue that asymmetrical treatment of men and women by the use of a language serve to make men appear more visible, central, and powerful than their female counterparts. This reinforcement of "maleness as the norm" impacts both cognition and culture, thereby reinforcing androcentric gender bias and maintaining patriarchal social structures (Hamilton, 1988; Merritt \& Kok, 1995).

However, there is not universal agreement that this form of asymmetry in language should be corrected or that it is even a problem. Those who reject the feminist critique often claim that cognition is independent of language and language does not influence culture (Stahlberg et al., 2007). Others argue that language is simply a vehicle to express thought (Wasserman \& Weseley, 2009) and cannot cause bias or influence sexist practices (Stahlberg et al., 2007). Still others support formal grammar rules and claim that the use of masculine generics should be maintained due to its status as historical convention (Martyna, 1980). Overall, those who oppose arguments against masculine generics reject the idea that eliminating masculine generics will help to include women or protect against other types of asymmetry. However, 
empirical evidence suggests that masculine generics do influence both cognition and behavior, and that eliminating their use helps to promote egalitarian attitudes and practices.

\section{Effects of Masculine Generics: Cognition and Imagery}

In the investigation of how the use of masculine generics affects cognition, studies have been conducted to investigate whether individuals who are familiar with formal grammatical rules are affected by the use of masculine generics. Miller and James (2009) provided participants with sentences with different types of pronoun usage and asked them if the sentences could apply to females, males and females, or just males. For sentences that used masculine generics, $96 \%$ of participants made at least one attribution error, and $27 \%$ had a $100 \%$ error rate - that is, they incorrectly interpreted the masculine generic as only applying to men $100 \%$ of the time. These effects held when controlling for people's own self-reported knowledge of formal grammar rules; even those who stated they understood the rules for using masculine generics made mistakes in its interpretation. These results reflect trends from over 30 years ago, when MacKay (1980) provided participants with textbook paragraphs that used the generic "he" and assessed their reading comprehension - in this study, $80 \%$ of participants who read genderbiased paragraphs made at least one pronoun attribution error, compared to $20 \%$ of participants who read passages with neologist pronouns (i.e., e, tey) and made one or more errors. These results indicate that even when masculine generics are used in a manner that is grammatically correct, individuals have difficulty interpreting them in a sense that is truly generic, with their use more often than not being attributed to male referents than female ones.

Other research has been concerned with how mental imagery is affected by the use of gender-biased language. Multiple studies have found that participants produce more images, pictures, and descriptions of male individuals than female individuals when given descriptions or 
prompts that contain masculine generics - and when the language is modified to either be gender-neutral or to include both men and women, these effects are greatly diminished (Cole, Hill, \& Dayley, 1983; Gastil, 1990; Hamilton, 1988; McConnell \& Fazio, 1996; Moulton et al., 1978; Schneider \& Hacker, 1973; Stahlberg, Sczesny, \& Braun, 2001). In one study, Stahlberg and colleagues (2001) asked people to name their favorite hero or musician. Participants were randomly divided into groups such that a third of them received the instructions written with masculine generics, a third received the instructions written with gender-neutral language ("they"), and a third received the instructions written with feminine/masculine word pairs ("he or she"). They found that participants who read instructions written with masculine generics produced more male exemplars than the other two conditions, regardless of participant gender. These effects are not limited to reading - Hamilton (1988) provided participants with sentence fragments and asked them to fill in the blanks, after providing them with examples that either cited the use of masculine generics or the use of gender-neutral language as correct. The researcher then asked the participants to describe the images in their head created by the sentences and to give a name to each of the persons in their imagery. The results of this study found that when participants were instructed to use masculine generics to fill in the blanks, they produced more male imagery and character names than female imagery and character names, at a ratio of 3.3 male responses to 1 female response; when participants used gender-neutral language, this ratio was 1.5 to 1 . Although this effect was much more pronounced for men than women, these results show that simply using masculine generics can create a cognitive bias, regardless of individual predisposition or sentence content. That is, the use of masculine generics makes it more difficult for someone to incorporate female persons into their mental representations, regardless of whether this language is modeled or self-generated. 


\section{Effects of Masculine Generics: Judgments and Behavior}

Research has also suggested that these cognitive differences are linked to changes in attitudes and behavior. One of the earliest examples of this was Bem and Bem's (1973) landmark study on the effects of sex-biased job advertising. The researchers found when high school seniors were given booklets that contained job descriptions with either sex-biased, sex-unbiased, or sex-reversed language, both male and female participants were significantly more likely to indicate interest in applying for a position that was written with unbiased or sex-reversed language as compared to job descriptions that were written in a way that was geared toward the opposite sex. They concluded that sex-biased language in job descriptions was a central component of sex-based job discrimination, with the language used affecting application rates for both genders. More recently, Stout and Dasgupta (2011) found that women who were exposed to gender-exclusive language during a mock job interview reported lower perceived belonging, motivation, and identification with the job, suggesting that this type of language can be used as a tool to signal group-based ostracism. A study with children found similar results; Vervecken, Hannover, and Wolter (2013) found that describing stereotypically male occupations in more neutral terms (i.e., with both male and female referents) strengthens young girls' ideas of accessibility for, and interest in, those careers. Other evidence can be found in examinations of hiring practices; Formanowicz and colleagues (2013) found that individuals were less willing to hire applicants who were described with "feminized" job titles, compared to their counterparts who were described with traditionally masculine job titles.

Perhaps one of the most compelling pieces of evidence, however, is a study conducted on the effects of masculine generics on legal decisions. Hamilton, Hunter, and Stuart-Smith (1992) assigned participants to serve in a mock jury trial that was considering a murder case where the 
defendant was pleading self-defense. The researchers told the participants to determine whether the woman had actually acted in self defense, and gave each participant a copy of the legal wording describing self-defense that was written with either gender-matching language ("he/she" or "she") or gender-biased language ("he"). They found that participants who read legal wording written with masculine generics were significantly more likely to find the woman guilty, with participants in the other two conditions significantly more likely to determine that she did act in self-defense. The researchers concluded that individuals who read a biased legal text might be unable to fully interpret it for cases involving women - a serious and potentially life-changing consequence.

\section{Why Do These Effects Exist?}

There may be various reasons as to why the use of masculine generics can influence cognition and behavior. Various explanations proposed by researchers include learned behavior, reinforcement, and priming effects.

\section{Learning and Reinforcement}

One of the simpler explanations of how masculine generics exert such influence is through theories of learning and reinforcement. Researchers have shown that gender stereotypes are created in young children (Hyde, 1984; Vervecken \& Hanover, 2015; Vervecken, Hannover, $\&$ Wolter, 2013), and use of masculine generics contributes to the early formation of genderrelated schemas (Hyde, 1984). Children struggle to process sexist language as neutral; for the literally inclined mind, a sentence that mentions a person as "he" is referring only to a male person. Although it is assumed that this male bias is corrected through formal education, studies with adults (McKay, 1980; Miller \& James, 2009) suggest that this confusion persists through adulthood. Although we may have been formally taught that masculine words can be intended as 
generic, it remains unclear when these words are intended to be generic and when they are intended to be specific male designations (Smith, Johnston-Robledo, McHugh, \& Chrisler, 2010) - and in the presence of ambiguity, we assume maleness, not generic designation, is intended (Merritt \& Kok, 1995). This masculine bias is then reinforced through repeated use of genderexclusive language, thereby promoting the socialization of sexist thinking (Gastil, 1990; Hamilton, 1988, Hellinger \& Bußmann, 2001; Stahlberg et al., 2001).

\section{Priming Effects}

Another explanation of this phenomenon is priming effects. One critical way we perceive and understand the world around us is to store information categorically, and gender is a particularly salient category that is used to process information about individuals (Garnham et al., 2012; Higgins, Rholes, \& Jones, 1977). Categories are strengthened by repeated activation, and the readiness with which a category is activated is referred to as its accessibility. According to McConnell and Fazio (1996), gender is a highly accessible category that can be activated through written communication. As gender is often a grammatical feature of language (Stahlberg et al., 2007), it is frequently used to describe individuals. The problem arises, then, when genderbiased language serves to repeatedly prime representations of one gender (i.e., maleness) over another (femaleness), reinforcing gender bias and influencing subsequent judgments.

Specifically, language that refers to gender activates gender-related constructs, making cognitive representations related to gender more salient. This increased salience serves as a prime, making cognitive representations and schemas more accessible and influencing expectations and judgments about individuals (Higgins et al., 1977; McConnell \& Fazio, 1996). This allows us to conclude that (1) when masculine generics are used, the construct of maleness is more frequently activated; (2) because the construct of maleness is more frequently activated, it is more readily 
accessible in information processing; and (3) higher accessibility of maleness means there is an increased likelihood that information will be processed in masculine-congruent ways. In contrast, when more inclusive language is used, it should be expected that there is increased activation (and therefore, increased accessibility) of female-congruent constructs, which would allow individuals to process information in more female-congruent ways.

In a demonstration of these priming effects, Wilson and $\mathrm{Ng}(1988)$ attached participants to a tachistoscope and presented a sentence in main view that either used masculine generics or feminine generics; in the secondary view, they briefly flashed either a male or female face. The faces were displayed for an extremely short period of time so that they could not be explicitly identified by the participants. The participants were then asked to identify the gender of the face they had viewed. Despite the use of male and female faces being equal frequency, they found that participants who were exposed to language that used masculine generics were more likely to guess that the face they had viewed was male (and vice versa for the participants that viewed language with feminine generics), such that males were overrepresented in the first condition and females were overrepresented in the second. In this case, reading sentences that primed either male or female mental representations increased the accessibility of those constructs, biasing the participants' ability to identify the target's gender.

Other studies have found evidence of priming effects as well. Lassonde and O'Brien (2013) conducted an eye-tracking study and presented participants with reading excerpts that contained information about individuals with gender-stereotyped occupations, along with a reference to the individuals' gender. In this case, the researchers found that participants' reading speed was affected by gender-stereotyped primes, such that reading speed was faster when the stereotyped primes were consistent with the gendered language that was used (e.g., "the 
electrician...he" was read faster and with fewer lookbacks than "the electrician...she"). The researchers suggested that gender-biased language can contradict other information that is presented in reading passages, adding to confusion and forcing participants to actively process the information in such a way as to resolve contradictions. They also suggested that the use of gender-inclusive language may not fully eliminate male bias, but it may help override it, especially when it is used together with other gender-relevant information. In a related study, Khan and Daneman (2011) studied lookbacks and processing time and found that man-suffix role terms (e.g., foreman) cause people to be more likely to ignore or exclude female referents, as they are inconsistent with the gendered prime presented, compared to role terms that are gender neutral (e.g., foreperson). They concluded, "gender-neutral uses of masculine terms might encourage readers 'to think male, rather than male and female"' (p. 352).

\section{Individual Difference Variables in Language Interpretation}

Individuals may be differentially affected by these types of language primes, based on other personal characteristics. Some of the biggest differences in interpretation are related to gender itself. Women are generally more sensitive to inclusive language primes and more receptive to proposed language reforms than men; they are also more likely to use genderinclusive language in everyday interactions (Conkright, Flannagan, \& Dykes, 2000; Martyna, 1980 Parks \& Roberton, 2004; Stahlberg et al., 2007). Khosroshahi (1989) explains this effect through the lens of Social Identity Theory (Tajfel, 1981, as cited in Khosroshahi, 1989) - women are more likely to interpret masculine generics as generic rather than masculine-specific because they want to promote their gender group and encourage a favorable group identity. Martyna (1980) agrees, asserting that women's use of gender-inclusive language promotes their own inclusion in cognitive processes and, therefore, inclusion into their own culture. 
Another variable that has been explored is attitudes towards women. Positive attitudes towards women are positively correlated with the use of more inclusive language, less biased interpretations of generic language, and openness to language reform (Parks \& Roberton, 2004). Individuals who display negative attitudes towards women have been found to use less inclusive language and resist language reform, even in countries where institutionalized language reforms are already in place (Sarrasin, Gabriel, \& Gygax, 2012). Measures of attitudes towards women are closely related to measures of sexism, which have also been explored as a moderating variable. Yet another is political views; measures of conservatism are related to attitudes towards women, which may explain the finding that individuals who identify as conservative are more likely to endorse gender-biased language (Formanowicz et al., 2013). However, conservatism is also defined in part by a tendency to value tradition and disparage change; therefore, the connection between conservatism and biased language use might be more about supporting conventional language styles than a sexist protest (Formanowicz et al., 2013).

\section{Alternative Solutions to Masculine Generics}

What, then, is to be done about masculine generics? Two strategies have been proposed to eradicate masculine generics and make language more gender fair: feminization and neutralization (Formanowicz et al., 2013; Stahlberg et al., 2007).

Feminization involves adding feminine forms of words to the English vocabulary in order to make the frequency of male to female references more equal (Formanowicz et al., 2013). Examples include creating labels that are specifically for women (e.g., author/authoress, actor/actress), as well as increasing the use of female gendered pronouns (e.g., using "she" generically in text; Formanowicz et al., 2013; Stahlberg et al., 2007). This helps strengthen the association of "women as people" by creating more female examples, thereby increasing 
women's visibility and allowing them to feel more included and "visualize" themselves in their own language (Formanowicz et al., 2013). This method has been found to result in lower levels of expressed sexism and less interpreted male bias in text (Madson \& Hessling, 1999).

Neutralization is the elimination of gender references within language and the addition of gender-neutral nouns and pronouns. Methods of neutralization include using male and female pronouns together as generic referents ("he/she"), using "they" as a singular generic pronoun, and creating gender-neutral alternatives for nouns (e.g., fireman into firefighter, chairman into chairperson, and mankind into humankind; Khan \& Daneman, 2011; Lassonde \& O'Brien, 2013; McConnell \& Fazio, 1996). This reduces gender asymmetry and allows individuals to picture the gender to which they are inclined without priming or cognitive interference (Martyna, 1980).

While research has shown that any type of neutral generic is better than using "he" or other types of masculine generics (Gastil, 1990), there are pros and cons to each alternative approach. Although neutralization attempts to remove explicit mention of gender from communication, it does not address the implicit People=Male bias. This bias would need to be addressed more explicitly, along with the incorporation of neutralized language, in order to have maximum impact. In terms of feminization, studies have found that the use of alternating pronouns was perceived as biased towards women (Madson \& Hessling, 1999), as well as lower in the quality of writing (Madson \& Shoda, 2006). It is unclear whether these effects are shortor long-term artifacts of language change. Some forms of feminization, such as adding specific female noun designations (actress), have been critiqued as simply being other types of asymmetry that contribute further to the greater problem of gender bias in language (see discussion of salience of female representation, above, Stahlberg et al., 2007). Preliminary studies in these areas have suggested that the use of neutralized pronouns (i.e., "they" as a 
singular pronoun, use of "he/she" together) may carry the least bias and allow for the greatest expression of gender-equal images (Gastil, 1990; Hamilton et al., 1992; Madson \& Hessling, 1999; Stahlberg et al., 2007).

Despite a definitive answer as to which approach of gender reform is the most effective, many institutions have made efforts to eradicate - or at least, condemn - the use of genderbiased language in formal communications. The American Psychological Association released guidelines several decades ago that recommended more gender-fair strategies be implemented in scientific writing and research (APA Publication Manual Task Force, 1977; Smith et al., 2010), and many other associations have made similar changes (e.g., Harper \& Row Publishers, Inc., 1976; Holt, Rinehart, \& Winston, 1976; John Wiley \& Sons, Inc., 1977). These changes have led to the ostensible elimination of masculine generics in academic publishing (Hegarty \& Buechel, 2006). Examination of many current formal guidelines may lead to the tempting conclusion that gender-biased language has fallen out of popular use and is no longer a pragmatic consideration for gender equality. However, this does not appear to be the case. Despite formal recommendations that advocate for the use of gender-fair language, there are many instances where gender-biased language and gender stereotypes are still being employed. A survey of academic textbooks in 1975 found that over $85 \%$ of them recommended the generic he (Bodine, 1975; McKay, 1980); more recent investigations have found that this proportion has improved, but many still employ gender-exclusive language (Foley \& Safran, 1994; Moser \& Hannover, 2014). There are also many other domains apart from academic publishing where masculine generics are still standard convention. One only need open a copy of the Bible to read the instruction, "If there is no interpreter, the speaker should keep quiet in the church and speak to himself and to God" (1 Corinthians 14:28; New International Version and King James Version). 
One particularly problematic domain is that of legal language. As described above, Hamilton and colleagues (1992) conducted a study where they found participants were significantly less likely to determine a woman had acted in self-defense if the legal language describing self-defense was written with masculine generics, compared to legal language written with more inclusive pronouns. Rose (2010) echoes the findings of Hamilton and colleagues (2012), presenting a critique of Supreme Court findings and suggesting that the use of masculine generics in legal language may lead legal scholars to conclude that the findings do not apply to women and promote a culture that endorses sexism and gender exclusion. These findings are particularly troubling, as many legal texts predate the language reform movement and still employ the use of masculine pronouns as generic.

\section{A Special Case of Masculine Generics: Foster Care in Illinois}

One such instance where gender-biased language is used in legal texts is in the regulation of the foster care system in Illinois. One legal document, the Licensing Standards for Foster Family Homes (LSFFH; Illinois General Assembly Joint Committee on Administrative Rules, 2012), specifies minimum requirements for foster homes and dictates standards of care for children who are wards of the state. Examples of standards dictated by the LSFFH are specifications for discipline, educational expectations, nutritional guidelines, and equitable treatment.

The LSFFH was originally drafted based on the Child Care Act of 1969 (Child Care Act of 1969; Illinois General Assembly Joint Committee on Administrative Rules, 2012) and is revised intermittently, based on perceived need. The process for making revisions to this legal document is complex. A committee of individuals are gathered and overseen by the Illinois Department of Child and Family Services (DCFS); this committee collects recommendations for 
revisions to the text based on input from various stakeholders, including DCFS staff, other private agency staff, community members, and political leadership. Once all the recommendations have been gathered, the committee submits the collection of proposed changes to the Illinois General Assembly. These changes are vetted and voted upon by a political committee before being incorporated into administrative rule. It is estimated that a single bout of revisions can take anywhere from three to five years, based on the efficiency of the committee as well as the general political climate in the state (M. Collins, personal communication, 19 January 2016).

The two most recent bouts of revisions to the LSFFH were approved in 2009 and 2012, respectively. In the 2009 revision, the entirety of the legal document was written with masculine generics. An example excerpt of this text appears as follows:

"Section $402.21 \ldots c)$ No child shall be subjected to corporal punishment, verbal abuse, threats or derogatory remarks about him or his family" (p. 35, section bolded for emphasis).

When the next round of revisions to this document took place in 2012, many instances of this type of wording were changed to reflect more gender-inclusive language practices. For example, the section detailed above was changed to state the following:

"Section $402.21 \ldots c)$ No child shall be subjected to corporal punishment, verbal abuse, threats or derogatory remarks about him or her or his or her family" (p. 35, bolded for emphasis).

This new version, albeit wordy, reflects a stance on behalf of the state to represent and advocate for all children in its care, regardless of gender. These types of changes are, in the view of many gender-equality advocates, both timely and necessary. However, these changes were not 
uniformly made throughout the document. While Section 402.21c) shows changes to the pronouns used in the licensing standards, other sections retain the gender-biased nature of the original versions. Section $402.21(\mathrm{~h})$, which states:

"A child may be temporarily restrained by a person physically holding the child if the child poses a danger to himself or to others" (2012, p. 35),

was not reworded in the 2012 revision, despite being found on the same page as 402.21 (c) and other standards that were reworded for gender inclusion. It is unclear why these changes to the wording were made for some standards but not for others.

But, do these changes really matter, or is this just a case of nitpicking the details? As stated above, opponents to gender-based language reform argue that changing something as small as a pronoun is not going to influence bias or help protect against discrimination based on sex (Stahlberg et al., 2007). Indeed, even other groups of individuals in the state of Illinois have maintained that going to the effort of changing legal documents to reflect gender-inclusive language is time-consuming, costly, and unnecessary (M. Grzybowski, personal correspondence, 14 January 2016). However, research has consistently found that changes to gender-based language can effect changes in cognition and behavior, even going so far as to make a difference in a jury verdict (Hamilton, Hunter, \& Stuart-Smith, 1992). Therefore, the purpose of this study is to explore whether the use of gender-biased language in the LSFFH creates priming effects that lead to the differential treatment of boys and girls in foster family homes.

Specifically, we aim to investigate the following:

- $\mathrm{RQ}_{1}$ : Does reading gender-biased language in the LSFFH create cognitive differences compared to those who read revisions written with gender-neutral language? 
- $\mathrm{RQ}_{2}$ : Do differences in gender-based language in the LSFFH create differences in how these standards are interpreted for boys versus girls?

- $\mathrm{RQ}_{3}$ : Are there specific traits or characteristics, such as participant gender or attitudes towards sexist language, that would create individual differences on the measurement of these questions?

\section{Overview of Current Study}

This study aims to investigate whether the use of gender-biased versus gender-neutral language in the LSFFH could potentially cause differential treatment for boys and girls in the foster care system in Illinois. It is expected that changes in wording of individual licensing standards will cause differential interpretation of the standards for children based on gender.

The design of this study was modeled after the research performed by Hamilton, Hunter, and Stuart-Smith (1992), who placed participants in a mock jury scenario and asked them to interpret legal language that was either written with gender-biased or gender-inclusive language. The design of this study was chosen due to the similarity of the content (interpretations of legal language for women) between our study and that of Hamilton and colleagues. It also appeared that the Hamilton et al. study, with a sample size of 72 participants, was statistically underpowered (computed post-hoc power from this study's reported statistics using G*Power version 3.0.10 found the analyses ranged in power from $0.55-0.83$ ). Therefore, many of our questions were modeled after their study, with the expectation that their significant results would be supported and their nonsignificant results rechecked with a higher-powered sample.

The design of this study also is unique in that it mirrors the way allegations of foster care misconduct are investigated by foster care workers in the state of Illinois. In private foster care agencies, there are workers whose duties include licensing foster homes and performing 
subsequent monitoring and oversight to ensure that licensed homes are following the rules set forth in the LSFFH. When an allegation of misconduct is received by one of these workers, there is a general process that is followed by these workers: (1) a worker receives and reviews a claim made by the reporting party; (2) the worker interviews all parties involved, including foster parents, to create a narrative of the situation; (3) the worker then compares the collected narrative with the printed regulations in the LSFFH and must decide, based on the specific wording of the rules, whether the foster parents behaved inappropriately. If the worker decides that one or more rules in the licensing standards were broken, the worker then works with the family, upper-level agency management, and DCFS and law enforcement personnel (if needed) to create a corrective plan to address the inappropriate behavior that took place (Rule 383, Illinois General Assembly Joint Committee on Administrative Rules, 2012).

The method of this study has the advantage of being an adaptation of Hamilton et al. (1992)'s study, but also mirroring the methods used by foster care workers to investigate allegations of misconduct. In this study, participants were presented with a hypothetical situation involving a foster child where an allegation of foster parent misconduct has been made in the home. The description of the foster child varied on whether the child was described as male or female. Participants were then provided with wording from the Licensing Standards from Foster Family Homes and asked to interpret the wording to decide whether the foster parents are guilty of breaking one of the rules or not. The Licensing Standards they received varied on whether they were written with gender-exclusive language (i.e., exclusive use of masculine generics) or gender-inclusive language (i.e., male/female pronoun pairs). If participants decided that the foster parents are guilty of breaking a rule, they were then asked to select an appropriate corrective action for the foster parents to receive. 


\section{Hypotheses}

The hypothetical situation given to all participants describes an altercation where a child is acting inappropriately to the point where they need to be physically restrained. All participants were then given an excerpt of the legal language that specifically includes the following statement:

"A child may be temporarily restrained by a person physically holding the child if the child poses a danger to himself(/herself) or others."

Given a literal reading of these rules, the correct interpretation would be that the foster parents in this scenario were following the foster care rules; therefore, even if the participants disagree with the parents' actions on a personal level, they should not find the foster parents guilty of inappropriate use of punishment. However, based on other research described above, we reasoned that the type of gendered language used in the rules would affect participants' determinations of foster parent guilt. If participants were given a hypothetical scenario where the gender of the child matches the subsequent gender mentioned in the legal language, we would expect this more consistent interpretation where participants determine that the foster parents were following the rules and should not be found guilty of inappropriate use of punishment. Therefore, we would expect that in the conditions where participants are given gender-inclusive language, participants would make more consistent determinations of non-guilt and elect for less severe corrective action.

The differences, then, should arise when participants are given gender-exclusive language. In conditions where participants are first primed with the description of a girl in foster care and then asked to interpret legal language where only masculine generics are used, there is a disconnect between the gender of the child mentioned and the gender of the child whose care is 
outlined in the LSFFH. This lack of female inclusion in gender-biased language may lead participants to determine that these rules are not applicable to females. Therefore, we expected participants in the female child / exclusive language condition would be less likely to determine that the guidelines apply to their hypothetical scenario and subsequently would be less likely to conclude foster parents' actions are protected by the foster care rules; these participants would be more likely to determine that the foster parents are guilty of inappropriate use of punishment and would choose more severe corrective action to rectify the situation than those in the other three conditions.

Another possibility could also be that we would see an opposite effect for participants in the male child / exclusive language condition. Participants in this condition were primed with male language in both areas, presumably leading to heightened activation of male constructs. This may lead to the increased activation of male stereotypes, one of which is that males are aggressive. Therefore, it may be that participants in this condition would be more likely to interpret that the child, consistent with male stereotypes, was behaving aggressively - it could be then, that participants decide that the foster parents not only acted appropriately, but needed to take the action that they did in order to regain control of the situation. For this reason, we expected that participants in the male child / exclusive language condition would be the most likely to determine that the foster parents are not guilty of inappropriate use of punishment and would choose the least severe corrective action of all four groups.

Based on these expectations, we hypothesized the following:

- $\mathrm{H}_{1}$ : Participants in the female child / exclusive language condition will be (a) more likely to determine that the legal language does not apply to female children, (b) more likely to determine that the foster parents are guilty of inappropriate use 
of punishment, and (c) will choose more severe corrective action to rectify the situation than those in the other three conditions.

- $\mathrm{H}_{2}$ : Participants in the male child / exclusive language condition (a) will be more likely to determine that the legal language does apply to male children, (b) will be the least likely to determine that the foster parents are guilty of inappropriate use of punishment, and (c) will choose the least severe corrective action to rectify the situation, compared to the other three conditions.

- $\mathrm{H}_{3}$ These effects will be mediated by the activation of gender constructs, such that (a) stronger activation of female constructs will lead participants to conclude that gender-exclusive legal language does not apply to the scenario, (b) stronger activation of male constructs will lead participants to conclude that genderexclusive legal language does apply to the scenario, and (c) those participants who express more activation of male or female constructs after reading the hypothetical situation will show stronger effects of the gender-exclusive language on their subsequent judgments than those with less activation (i.e., restraint of male children is specifically allowed by the rules, whereas restraint of female children is not specified and therefore more likely to be condemned).

- $\mathrm{H}_{4}$ : Attitudes towards nonsexist language will moderate these effects, such that individuals who are more likely to recognize language as sexist and have more positive attitudes towards nonsexist language will not be as affected by the use of gender-exclusive language than those who are less able to recognize sexist language and have more negative attitudes towards nonsexist language use. 
- $\mathrm{H}_{5}$ : Levels of self-reported sexism will moderate these effects, such that individuals who score lower in modern sexism will not be as affected by the use of gender-exclusive language than those who score higher in modern sexism. 


\section{CHAPTER III: METHOD}

\section{Participants}

Participants were recruited using Amazon's Mechanical Turk and were offered $\$ 0.25$ for their participation in an online survey. Participation was limited to those who speak proficient English and who reside in North America. Participation was not limited based on hit approval percentage. Key search terms used to describe the study included "survey," "psychology," "attitudes," and "science." A power analysis using G*Power version 3.0.10 was performed to determine that, assuming a medium effect size (effect size $f=0.25, \alpha=.05$, power $=0.95$; based on calculations from statistics reported by Hamilton et al., 1992), a minimum sample size of 210 participants was needed to ensure sufficient power.

Three hundred six participants initially responded on Mechanical Turk; however, 32 participants were excluded from analyses for not completing the survey or giving incoherent answers. The final data set consisted of 274 participants. Of the final sample, $169(61.7 \%)$ participants identified as female, $102(37.2 \%)$ participants identified as male, and $3(1.1 \%)$ participants identified as transgendered (to ensure comparable group sizes, the three transgendered participants were excluded from analyses when participant gender was examined as a potential main effect). The average participant age was $34.91(S D=11.65)$ years, with reported age ranging from 19 to 66 years old. The sample was predominantly White (77.0\%), with $6.6 \%$ identifying as Black/African American, 5.8\% identifying as Hispanic/Latino, 3.3\% identifying as Asian, 6.2\% identifying as another race (other race selections included American Indian, Middle Eastern, and East Indian), and 1.1\% choosing not to identify their race. The sample was predominantly well educated, with 101 participants $(36.9 \%)$ having completed some college, 105 participants (38.3\%) having a college degree, 32 participants $(11.7 \%)$ having 
completed a Master's degree, and 7 participants (2.6\%) having completed education higher than a Master's degree. Only 27 participants $(9.9 \%)$ had a high school degree or equivalent or less.

\section{Design and Procedure}

Data were collected through completion of participant surveys, with a 2 (gender of child: male vs. female) $\times 2$ (language type: gender-exclusive or gender-inclusive) between-subjects factorial design. Participants were asked to participate in a study to investigate the clarity and accuracy of the wording in the Illinois Licensing Standards for Foster Family Homes. Full versions of the survey can be found in Appendix A and will be described briefly here.

After completing an informed consent form, participants were asked to read some basic information that defines the term "foster child" and describes foster care in Illinois. Participants were given the following prompt:

Imagine you are an individual who has been charged with evaluating allegations of misconduct in the foster care system. In this task, you will read about a situation where foster parents may or may not have broken one or more of the rules governing the treatment of foster children placed in their home. Your job is to interpret the rules given and decide whether the foster parents acted inappropriately. If you decide that a rule was broken, you will then be asked to choose what an appropriate punishment might be for this situation.

Participants then read a short excerpt describing a foster child. Participants were randomly assigned to the "Male Child" condition, where the child is described as a boy named James, or to the "Female Child" condition, where the child is described as a girl named Jen. The vignette read as follows (text bolded here for emphasis): 
James/Jen is an 11-year-old boy/girl who is currently placed in foster care. He/she has been living in his/her current foster home for about 6 months. James/Jen has a history of behavioral issues, and he/she often acts out when he/she does not get his/her way. The other day, James/Jen had a tantrum when he/she was not allowed to watch TV. He/She began screaming and throwing his/her possessions around his/her room. James'/Jen's foster parents pinned him/her to the floor (i.e., held down his/her hands and feet) until he/she calmed down and agreed to sit in time-out.

After reading the vignette, participants were asked to complete a short open-ended question to describe their general impression of the child. They were then told that the foster parents were reported to foster care authorities by a neighbor, and that it is the participant's job to read a relevant excerpt of the foster care standards and determine whether a rule was broken by the foster parents. Again through random assignment, participants were sorted into conditions that vary on the language of the foster care standards; half read standards that were written entirely with masculine generics (i.e., "A child may be temporarily restrained by a person physically holding the child if the child poses a danger to himself or others"), and half read standards that were modified with gender-inclusive language (i.e., "A child may be temporarily restrained by a person physically holding the child if the child poses a danger to himself/herself or to others"; full examples of the prompts can be found in Appendix A). After reading the excerpt of the foster care standards, participants were asked to evaluate the situation and indicate if the rules were broken and the extent to which the foster parents should receive disciplinary action. They then completed an individual difference measure and a demographics questionnaire before being debriefed and thanked. 


\section{Measures}

\section{Open-Ended Response}

Participants were asked to describe their general impression of the foster child. These responses were coded to determine the extent to which participants displayed activation of gendered constructs (i.e., use of gendered pronouns and gender-explicit descriptions), which was used as a manipulation check in the moderated mediation model. Coding was assisted through use of Linguistic Inquiry Word Count (LIWC; Pennebaker, Booth, Boyd, \& Francis, 2005), a software program that provides automated coding of open-ended responses based on prespecified criteria. LIWC processes text by sorting words into categories or "dictionaries" that represent subjects of interest. LIWC software then provides a series of scores for each response on a variety of dimensions, with each score representing a proportion of how many words from the specific category are used in comparison to the total number of words in the response (Pennebaker et al., 2005; Tausczik \& Pennebaker, 2010). The categories of interest in this analysis were the "male" and "female" categories, which scored the proportion of words used in each response that represented explicitly male or female referents, respectively (e.g., words such as "he", "his", and "him" are coded as male, while words such as "she", "her", and "hers" are coded as female). Male scores were coded as positive, and female scores were coded as negative. A participant's "male" and "female" LIWC scores were then combined to form a total LIWC score, with a final positive score representing greater activation of male constructs and a final negative score representing greater activation of female constructs. Alternate forms of manual coding were performed as well, such as counting how many times participants explicitly mentioned the child by name in their open-ended response and adding these to their "male" or "female" scores as a representation of gender activation. 


\section{Indication of Aggression}

Participants were asked, "Do you think James/Jen was behaving aggressively?” They were asked to select their answer on a 7-point Likert scale, with $1=$ "This child was not behaving at all aggressively" and $7=$ "This child was definitely behaving aggressively." This question was designed to help test our hypothesis that greater activation of male constructs leads to greater activation of male-specific gender stereotypes.

\section{Perceived Applicability of the Licensing Standards}

After reading the excerpts from the foster care standards, participants were first asked one question: "Do you think the guidelines described here are directly applicable to what happened with James/Jen?" They were asked to select their answer on a 7-point Likert scale, with $1=$ "No, not at all" and 7 = "Yes, definitely." This question was also used in mediation analyses (described below).

\section{Evaluation of the Scenario}

After determining whether the licensing standards are applicable to the James/Jen scenario, participants were then asked to make a determination of guilt: "Based on the guidelines described above, do you think these foster parents are guilty of inappropriate use of discipline?" Participants were asked to answer this question "yes" or "no." Following this question was a second question that asked participants what type of corrective action they believed the foster parents should receive for the incident. Participants were given seven options to choose from for a potential corrective action. The options ranged in severity from "No corrective action needed" to "They should lose their foster care license and be charged with child abuse." These two questions were used to test whether perceived applicability of the legal language affects its 
interpretation, as well as whether selections of punishment for the foster parents varied by participant condition.

\section{Attitudes Towards Sexist/Nonsexist Language}

After completing their evaluations of the hypothetical scenario, participants were asked to complete the Inventory of Attitudes Towards Sexist/Nonsexist Language - General (IASNL-G; Parks \& Roberton, 2000, 2004, 2005). The IASNL-G is a questionnaire that assesses participant attitudes towards sexist language, including its prevalence and use, as well as participants' willingness to identify language as sexist. It has 21 items that participants are asked to respond to on a 5-point Likert scale. The questionnaire first presents a definition of sexist language and then ask participants to indicate how much they agree with statements such as, "Women who think that being called a 'chairman' is sexist are misinterpreting the word 'chairman"' (a full version of the questionnaire can be found in Appendix A). The IASNL-G has been shown to positively correlate with measures of attitudes towards women, perspective taking, and empathy. It negatively correlates with measures of neosexism (Parks \& Roberton, 2004, 2005), an attitudinal measure representing an internal conflict between endorsement of egalitarian values and negative feelings towards women (Tougas, Brown, Beaton, \& Joly, 1995). Additionally, it is able to discriminate between advocates for nonsexist language and non-advocates. In previous studies, it has been shown to have good content and construct validity, as well as good internal consistency ( $\alpha=.84-.94$, Parks \& Roberton, 2000, 2004, 2005); however, in this sample, internal consistency was lower than expected $(\alpha=.67)$.

\section{Modern Sexism Scale}

Participants were asked to complete the Modern Sexism Scale (MSS; Swim, Aikin, Hall, \& Hunter, 1995), a 13-item questionnaire that assesses sexist beliefs. The Modern Sexism Scale 
consists of two subscales: the Old-Fashioned Sexism subscale consists of five items that assess "traditional" stereotypical beliefs about gender (e.g., "Women are just as capable of thinking logically as men"), and the Modern Sexism subscale consists of eight items assessing attitudes towards women who demand equal rights and willingness to acknowledge continuing gender discrimination in modern society (e.g., "Discrimination against women is no longer a problem in the United States," Swim et al., 1995). Participants are asked to indicate the extent to which they agree with each item on a 5-point Likert scale, with $1=$ Strongly Agree and $5=$ Strongly Disagree. The items in the Modern Sexism subscale help control for social desirability in that they are not as readily identified as sexist, especially in contrast to the Old-Fashioned sexism items, thus providing a more subtle measure of sexism (Campbell, Schellenberg, \& Senn, 1997; Hitlan, Pryor, Hesson-McInnis, \& Olson, 2009; Swim et al., 1995; Swim, Mallett, RussoDevosa, \& Stangor, 2005). Scores on the Modern Sexism Scale have been found to significantly positively correlate with neosexism (Campbell et al., 1997). Scores also negatively correlate with attitudes toward feminism and the Women's Movement (Campbell et al., 1997), and men have been found to generally score higher on the scale than women (Campbell et al., 1997; Swim et al., 1995). In this sample, internal consistency scores for both subscales were acceptable $(\alpha=.86$ for the Modern Sexism subscale and $\alpha=.73$ for the Old-Fashioned Sexism subscale).

\section{Demographics}

Participants were asked to identify their gender, age, highest level of education, and ethnicity. 


\section{CHAPTER IV: RESULTS}

\section{Open-Ended Responses}

Open-ended responses were coded in the manner described above, and participants were each given a total LIWC score. LIWC scores ranged from -33.33 to 28.57 , with more positive scores representing greater male activation and more negative scores representing greater female activation. Activation of gendered constructs significantly differed based on condition in that participants in the male child conditions $(M=9.96, S D=5.44)$ had higher mean LIWC scores than participants in the female child conditions $(M=-9.74, S D=5.72), t(272)=29.19, p<.001$, $d=3.53$. This shows that male and female constructs were differentially activated for those in the male and female child conditions. However, while participants showed differential activation of male and female constructs across conditions, absolute values of activation did not significantly differ, indicating that participants showed similar levels of activation across conditions. That is, participants in the male child conditions showed activation of male constructs $(M=9.96, S D=5.44)$ in levels similar to that in which participants in the female child conditions showed activation of female constructs $(M=9.74, S D=5.72), t(272)=0.33, p=.74$, $d=0.04$. Participants also did not show cross-activation of gendered constructs across conditions - that is, participants in the male child condition did not display activation of female constructs (i.e., they used words such as "his" and "him" but did not use words such as "she" and "hers"), and vice versa.

\section{Descriptive Statistics}

Table 1 shows, for the entire sample, the means, standard deviations, and correlations for the four dependent variables and the three proposed moderator variables: perceived aggressiveness of the child, perceived applicability of the foster care rules, determination of 
guilt, corrective plan chosen, IASNL-G score, MSS - Old-Fashioned Sexism score, and MSS Modern Sexism score. General ratings of child aggression, applicability of the licensing standards, and severity of the corrective plan were high, with average ratings above the midpoint of 4.0. Participants also generally tended to find the foster parents not guilty of inappropriate use of punishment regardless of condition, with 207 (75.5\%) participants stating a rule was not broken and only 67 (24.5\%) individuals stating a rule was broken in the scenario. Correlations between the dependent variables indicate that perceptions of aggressiveness, applicability, and guilt of the foster parents are all significantly related, as well as that applicability and determination of guilt are significantly related to the severity of corrective plan chosen. A series of one-way Analyses of Variance (ANOVAs) were conducted to test whether demographic variables affected ratings of the situation, regardless of condition. These analyses found no significant main effect of gender $(F \mathrm{~s}=0.20-3.03, p \mathrm{~s}=.08-.65, \eta \mathrm{s}=.00-.01)$ or education $(F \mathrm{~s}=$ $0.27-1.15, p \mathrm{~s}=.33-.97, \eta \mathrm{s}=.01-.03)$ on ratings of perceived aggression of the child, applicability of the licensing standards, determination of guilt, or severity of corrective plan chosen. Participant age was significantly positively correlated with ratings of the child's aggression $(r=0.22, p<.001)$ and perceived applicability of the licensing standards $(r=0.16, p$ $=.009)$, but not significantly correlated with determinations of foster parent guilt $(r=0.01, p=$ $.90)$ or severity of corrective plan chosen $(r=-0.02, p=.78)$. Ratings of the child's aggression did not differ based on whether participants read about a female child $(M=5.33, S D=1.31)$ or a male child $(M=5.45, S D=1.47), t(272)=0.71, p=.48, d=.09$. Although ratings of the child's aggressiveness were normally distributed, participant ratings were negatively skewed for applicability (skewness $=-1.24, S E=.15$ ) and positively skewed for severity of corrective plan (skewness $=1.55, S E=.15)$, suggesting non-normality in participant responses. 
Table 1 also shows the means, standard deviations, and correlations for scores on the IASNL-G, the MSS - Modern Sexism subscale, and the MSS - Old-Fashioned Sexism subscale. Scores on the IASNL-G did not significantly differ based on participant gender, age, or education $(F \mathrm{~s}=0.00-1.79, p \mathrm{~s}=.09-.99, \eta \mathrm{s}=.00-.18)$, and scores on the MSS subscales did not significantly differ based on participant age or education $(F \mathrm{~s}=0.73-1.16, p \mathrm{~s}=.24-.65, \eta \mathrm{s}=.02-$ .19). For the MSS - Old-Fashioned Sexism subscale, male participants $(M=12.72, S D=6.38)$ scored significantly higher than female participants $(M=10.07, S D=6.15), t(268)=3.38, p=$ $.001, d=.42$. Results were similar for the MSS - Modern Sexism subscale, with male participants $(M=28.5, S D=9.70)$ scoring significantly higher than female participants $(M=$ 23.63, $S D=10.43), t(269)=3.83, p<.001, d=.48$. These gender differences are consistent with previous studies (Campbell et al., 1997; Swim et al., 1995) that have found men score higher in sexism than women. Old-Fashioned Sexism was also correlated with several of the dependent variables; participants higher in Old-Fashioned Sexism tended to find the licensing standards less applicable, were more likely to find the foster parents guilty of inappropriate use of punishment, and tended to choose more severe corrective plans than those lower in Old-Fashioned Sexism. 
Table 1

Descriptive Results and Correlations Among Perceived Aggression, Applicability of Licensing Standards, Determination of Guilt, and Corrective Plan

\begin{tabular}{llllllll}
\hline Measures & Mean $(S D)$ & $(1)$ & $(2)$ & $(3)$ & (4) & (5) & (6) \\
\hline (1) Aggression of Child & $5.39(1.39)$ & --- & --- & --- & --- & --- & --- \\
(2) Applicability of Standards & $5.74(1.68)$ & $.30^{* *}$ & --- & --- & --- & --- & --- \\
(3) Determination of Guilt & $.24(.43)$ & $-.17^{*}$ & $-.24^{* *}$ & --- & --- & --- & --- \\
(4) Severity of Corrective Plan & $.88(1.48)$ & -.01 & $-.22^{* *}$ & $.74^{* *}$ & --- & --- & --- \\
(5) IASNL-G & $60.69(9.48)$ & -.10 & -.04 & $.14^{+}$ & $.16^{*}$ & --- & --- \\
(6) MSS - Old-Fashioned Sexism & $25.51(10.37)$ & -.11 & $-.25^{* *}$ & $.17^{*}$ & $.16^{+}$ & -.12 & --- \\
(7) MSS - Modern Sexism & $11.14(6.36)$ & .02 & -.05 & -0.00 & .02 & $-.48^{* *}$ & $.44^{* *}$
\end{tabular}

Note. ${ }^{+} \mathrm{p}<.05,{ }^{*} \mathrm{p}<.01,{ }^{* *} \mathrm{p}<.001$. IASNL-G scores range from $21-105$. High IASNL-G scores indicate positive attitudes towards the use of nonsexist language. MSS - Old-Fashioned Sexism scores range from 5-35, and high scores indicate high levels of sexism. MSS - Modern Sexism scores range from 8-56, and high scores indicate high levels of sexism.

\section{Effect of Condition on Perceived Applicability of Licensing Standards}

To test whether participant condition significantly affected participant judgments of whether the legal language directly applied to the hypothetical scenario, we conducted a 2 (language type: gender-exclusive or gender-inclusive) $\times 2$ (gender of child: male or female) between-subjects ANOVA on the dependent variable of perceived applicability of the licensing standards to the hypothetical scenario. This analysis found no significant main effects (language 
type: $F[1,270]=1.75, p=.19, \eta_{p}{ }^{2}=.006$; gender of child: $F[1,270]=0.85, p=.36, \eta_{p}{ }^{2}=.003$ ) and no significant interaction $\left(F[1,270]=0.31, p=.58, \eta_{p}{ }^{2}=.001\right)$ for perceived applicability of the licensing standards.

\section{Effect of Condition on Determination of Guilt}

To test whether participant condition affected determination of whether the foster parents are guilty of inappropriate use of punishment, we performed a chi-square test of association for two categorical variables. The dependent variable was determination of guilt ("yes" or "no") and the grouping variable was participant condition. Table 2 provides a cross-classification between condition and judgments of guilt. These frequencies did not exhibit a significant association between condition and judgments of guilt, $\chi^{2}(3, N=274)=2.19, p=.53$.

Table 2

Cross-Classifications Between Participant Condition and Determination of Foster Parent Guilt

\begin{tabular}{llllll}
\hline Determination of Guilt & Condition 1 & Condition 2 & Condition 3 & Condition 4 & Total \\
\hline Not Guilty & 53 & 52 & 51 & 51 & 207 \\
Guilty & 19 & 17 & 11 & 20 & 67 \\
Total & 72 & 69 & 62 & 71 & 274 \\
\hline
\end{tabular}

\section{Effect of Condition on Determination of Corrective Action}

To test whether participant condition affected severity of corrective action chosen, we conducted a 2 (language type: gender-exclusive or gender-inclusive) $\times 2$ (gender of child: male or female) between-subjects ANOVA on the dependent variable of type of corrective action needed. Participants were asked to choose from seven different options for corrective action for 
the foster parents, ranging from "no corrective action needed" to "they should lose their foster care license AND be charged with child abuse." This analysis found no significant main effect of language type $\left(F[1,265]=0.12, p=.73, \eta_{p}{ }^{2}=.000\right)$, no significant main effect of gender of child $\left(F[1,265]=3.15, p=.08, \eta_{p}{ }^{2}=.01\right)$, and no significant interaction $(F[1,265]=0.28, p=$ $\left..59, \eta_{p}{ }^{2}=.001\right)$ on the severity of corrective action chosen.

We performed additional analyses to determine whether attitudes towards sexist/nonsexist language and modern sexism act as moderators of type of corrective action chosen. We performed three additional General Linear Model analyses on the dependent variable of type of corrective action chosen, using gender of child and language type as independent variables and including each of the participant individual differences scores one at a time. MSSModern Sexism did not have a main effect $\left(F[1,261]=0.31, p=.578, \eta_{p}{ }^{2}=.001\right)$ and did not interact with any of the other independent variables as a significant moderator, $F \mathrm{~s}=0.02-0.75$,

$p \mathrm{~s}=.389-.904, \eta_{p}{ }^{2} \mathrm{~s}=.000-.003$. MSS-Old-Fashioned Sexism showed a main effect on severity of corrective action chosen $\left(F[1,260]=6.87, p=.009, \eta_{p}{ }^{2}=.03\right)$; however, it did not interact with any of the other independent variables as a significant moderator, $F \mathrm{~s}=0.05-1.21, p \mathrm{~s}=.272$ $.827, \eta_{p}{ }^{2} \mathrm{~s}=.000-.005$. Finally, there was a main effect of IASNL-G on severity of corrective action chosen $\left(F[1,261]=7.00, p=.009, \eta_{p}{ }^{2}=.03\right)$, but it did not interact with any of the other independent variables as a significant moderator, $F \mathrm{~s}=0.02-1.44, p \mathrm{~s}=.231-.895$, $\eta_{p}^{2} \mathrm{~s}=.000-.005$

\section{Moderated Mediation Analysis: Gender of Child as a Priming Effect}

We hypothesized a moderated mediation model to explain the expected relationships between gender of the child, type of legal language used, participant sexism, and perceived applicability of the licensing standards. The hypothetical model can be seen in Figure 1. We 
hypothesized that reading about a specific child in the hypothetical scenario would lead to the heightened activation of gendered constructs (measured by LIWC score). Modern sexism was expected to moderate this relationship, with higher levels of sexism leading to greater activation (and subsequent display) of gendered constructs and lower levels of sexism linking to lower activation and display of gendered constructs. The activation of gendered constructs would then either conflict with the legal language presented (i.e., for those who read about a female child and then were presented with gender-exclusive legal language), leading to a decrease in perceived applicability of the licensing standards, or align with the legal language presented (i.e., for those who were presented with gender-inclusive legal language or for those who read about boys and then read male-exclusive language), leading to an increase in perceived applicability of the licensing standards.

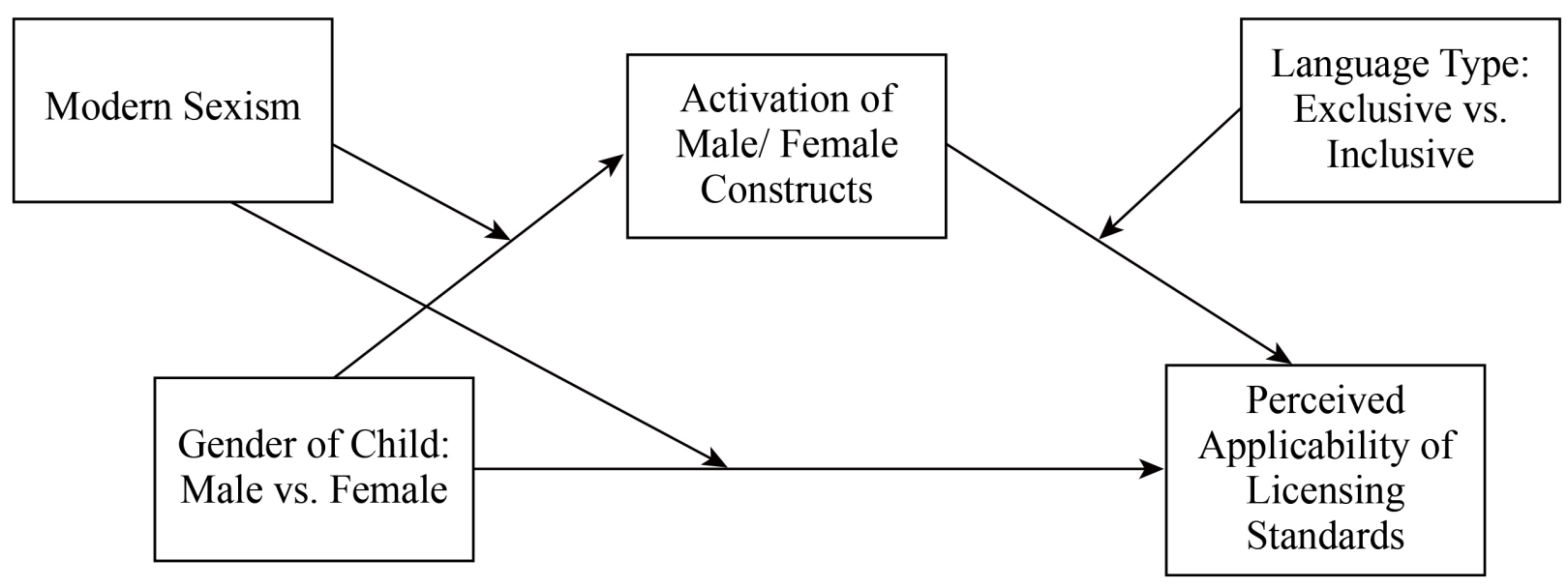

Figure 1. Proposed moderated mediation model using Modern Sexism as a moderator. 
We used the PROCESS macro for SPSS developed by Hayes $(2013,2015)$ and tested our hypothetical model against model 22 of the PROCESS macro. Gender of child and language type were each coded as -1 and 1 ( -1 for female child and gender-neutral language, 1 for male child and gender-biased language). Significance of the model was determined both by examining the coefficients of the overall model and by using bootstrapping procedures $(N=10000)$ to calculate $95 \%$ confidence intervals for unstandardized coefficients of the individual paths. The paths tested by this model can be seen in Figure 2, and results from these analyses can be seen in Table 3. As seen in Table 3, the overall model was significant for paths leading to the activation of gendered constructs, $\left(R^{2}=0.76, F[3,270]=286.25, p<.001\right)$, and examination of the individual paths shows that the gender of the child significantly influenced the activation of male/female constructs. However, the overall model was not significant for paths leading to the perceived applicability of licensing standards, $\left(R^{2}=0.01, F[6,267]=0.67, p=.67\right)$, and none of the individual paths leading to perceived applicability were significant. This analysis was repeated with MSS - Old-Fashioned Sexism substituted for MSS - Modern Sexism as an indicator of sexism, and a similar pattern of results was found, with one exception. When Old-Fashioned Sexism was used as a moderator variable, it exerted a main effect upon perceived applicability ( $b$ $=-0.07, s e=0.02, p<.001$ ), indicating a negative relationship between this measure of sexism and perceived applicability of the standards. However, Old-Fashioned Sexism did not interact with any other variables, and the overall pattern of results remained non-interpretable. 


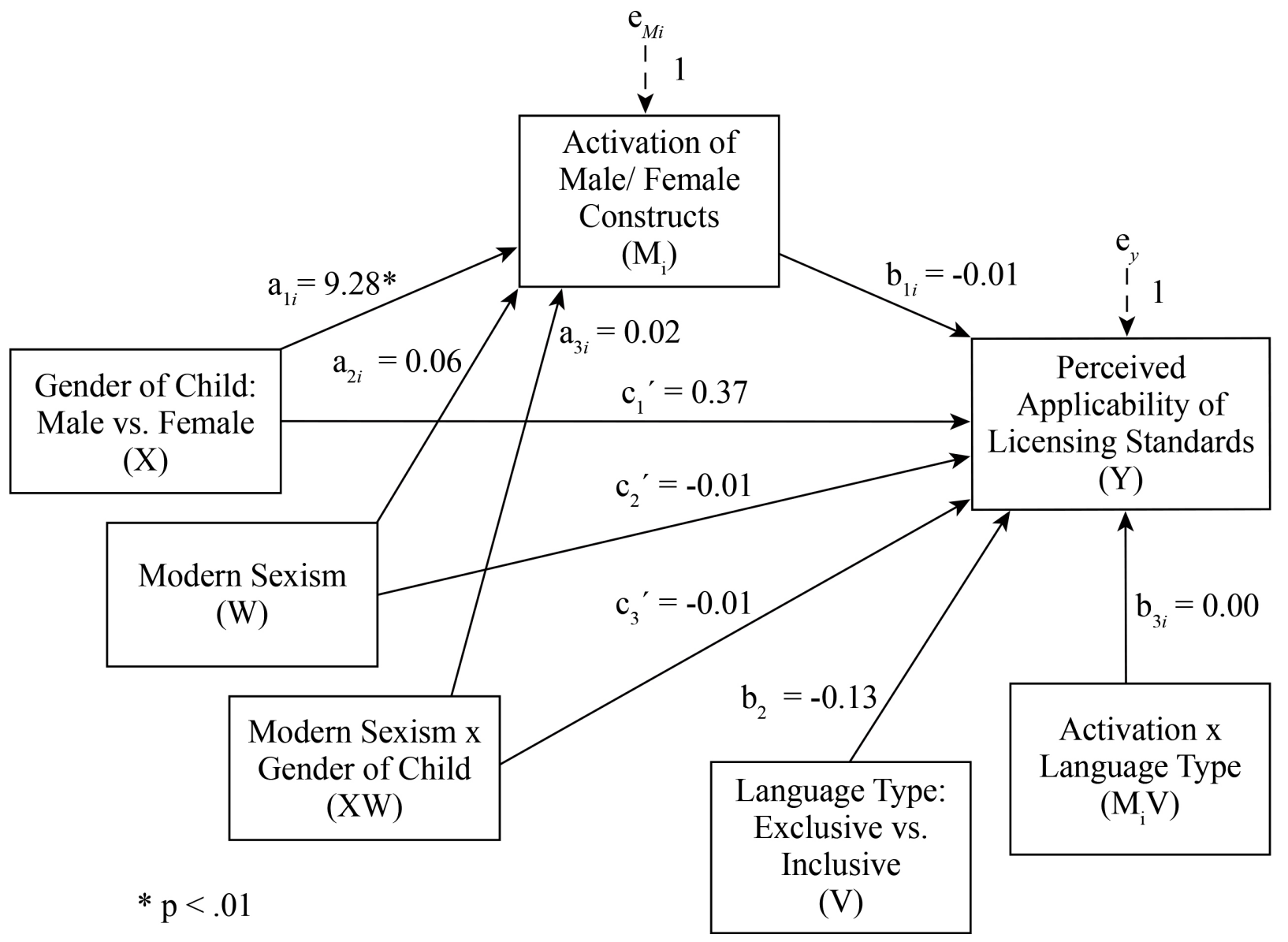

Figure 2. Statistical representation of Figure 1 with unstandardized regression paths denoted. 
Table 3

Model Coefficients for the Conditional Process Model in Figure 2

\begin{tabular}{|c|c|c|c|c|c|c|c|c|c|c|}
\hline \multirow[b]{3}{*}{ Antecedent } & \multicolumn{10}{|c|}{ Consequent } \\
\hline & & \multicolumn{4}{|c|}{$M$ (Activation of Constructs) } & & \multicolumn{4}{|c|}{$Y$ (Perceived Applicability) } \\
\hline & & Coeff. & $S E$ & $L L C I$ & $U L C I$ & & Coeff. & $S E$ & $L L C I$ & $U L C I$ \\
\hline$X$ (Gender of Child) & $a_{1 i}$ & 9.28 & 0.90 & 7.50 & 11.05 & $c_{1}^{\prime}$ & 0.37 & 0.32 & -0.27 & 1.00 \\
\hline$M$ (Activation) & & - & - & - & - & $b_{1 i}$ & -0.01 & 0.02 & -0.04 & 0.03 \\
\hline$W$ (Modern Sexism) & $a_{2 i}$ & 0.06 & 0.03 & -0.01 & 0.12 & $c_{2}^{\prime}$ & -0.01 & 0.01 & -0.03 & 0.01 \\
\hline$X \times W$ & $a_{3 i}$ & 0.02 & 0.03 & -0.04 & 0.09 & $c_{3}^{\prime}$ & -0.01 & 0.01 & -0.03 & 0.01 \\
\hline$V$ (Language Type) & & - & - & - & - & $b_{2}$ & -0.13 & 0.10 & -0.33 & 0.07 \\
\hline$M \times V$ & & - & - & - & - & $b_{3 i}$ & 20.00 & 0.01 & -0.02 & 0.02 \\
\hline \multirow[t]{2}{*}{ Constant } & $i_{1}$ & -1.32 & 0.90 & -3.10 & 0.46 & $i_{2}$ & 5.97 & 0.27 & 5.43 & 6.50 \\
\hline & \multicolumn{5}{|c|}{$R^{2}=0.76$} & \multicolumn{4}{|c|}{$R^{2}=0.01$} & \\
\hline
\end{tabular}

We had also hypothesized that IASNL-G scores could also play a role in influencing perceived applicability of the licensing standards; thus, a secondary model was developed and tested. This hypothetical model can be seen in Figure 3. As this model shows, we hypothesized that reading the hypothetical scenario would activate gendered constructs. This activation would influence perceived applicability of the licensing standards, based on whether the participants were presented with gender-exclusive or gender-inclusive language. However, in this model interpretation of the exclusive/inclusive language was moderated by attitudes towards sexist/nonsexist language, with higher IASNL-G scores predicting a weaker relationship between gender-exclusive language and perceived application of the language to the scenario at hand. The statistical model, seen in Figure 4, was tested against model 18 of the PROCESS macro. As can be seen in Table 4, the overall model was significant for paths leading to the activation of 
gendered constructs $\left(R^{2}=0.76, F[1,272]=852.14, p<.001\right)$, and examination of the individual paths shows that the gender of the child significantly influenced the activation of male/female constructs. However, the overall model was not significant for paths leading to the perceived applicability of licensing standards, $\left(R^{2}=0.03, F[8,265]=0.92, p=.50\right)$, and although some of the individual paths leading to perceived applicability approached significance $(p<.10)$, none reached the $p<.05$ level and all confidence intervals straddled zero.

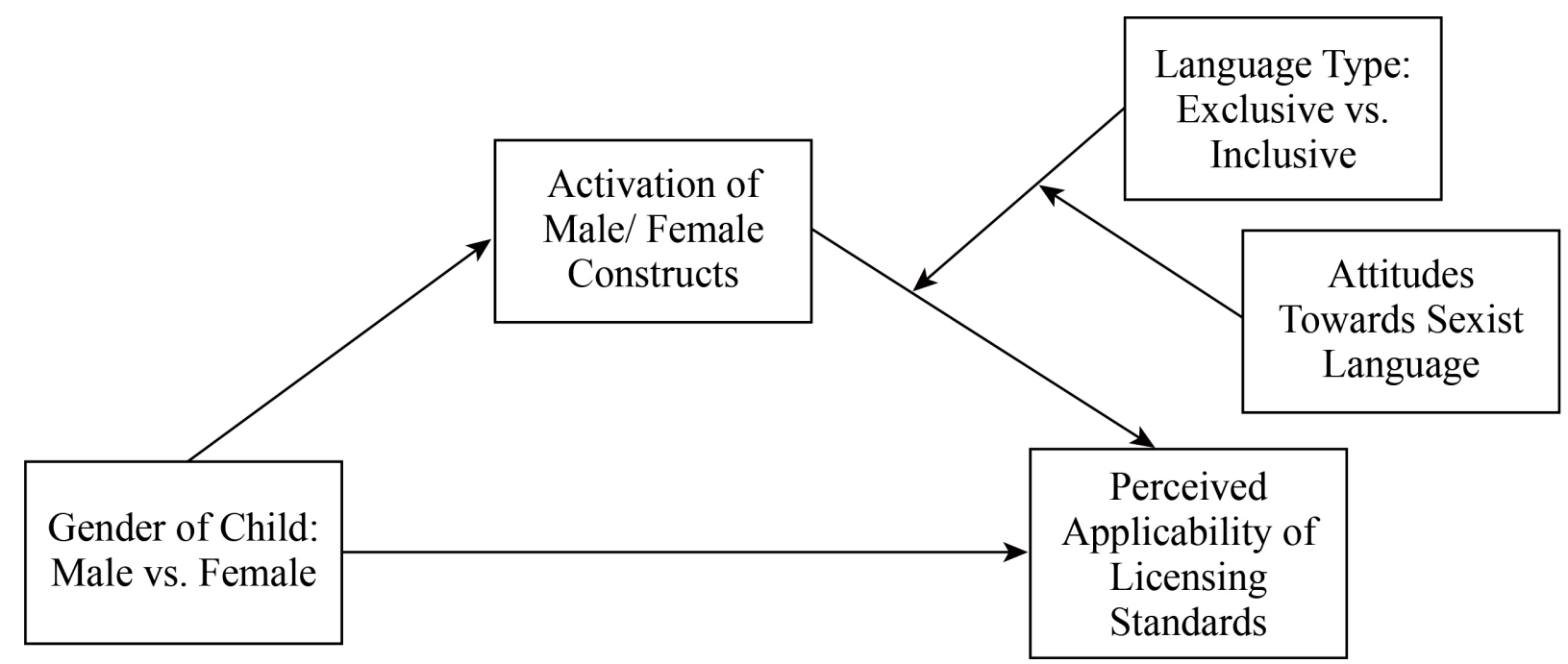

Figure 3. Proposed moderated mediation model using Attitudes Towards Sexist/Nonsexist Language as a moderator. 


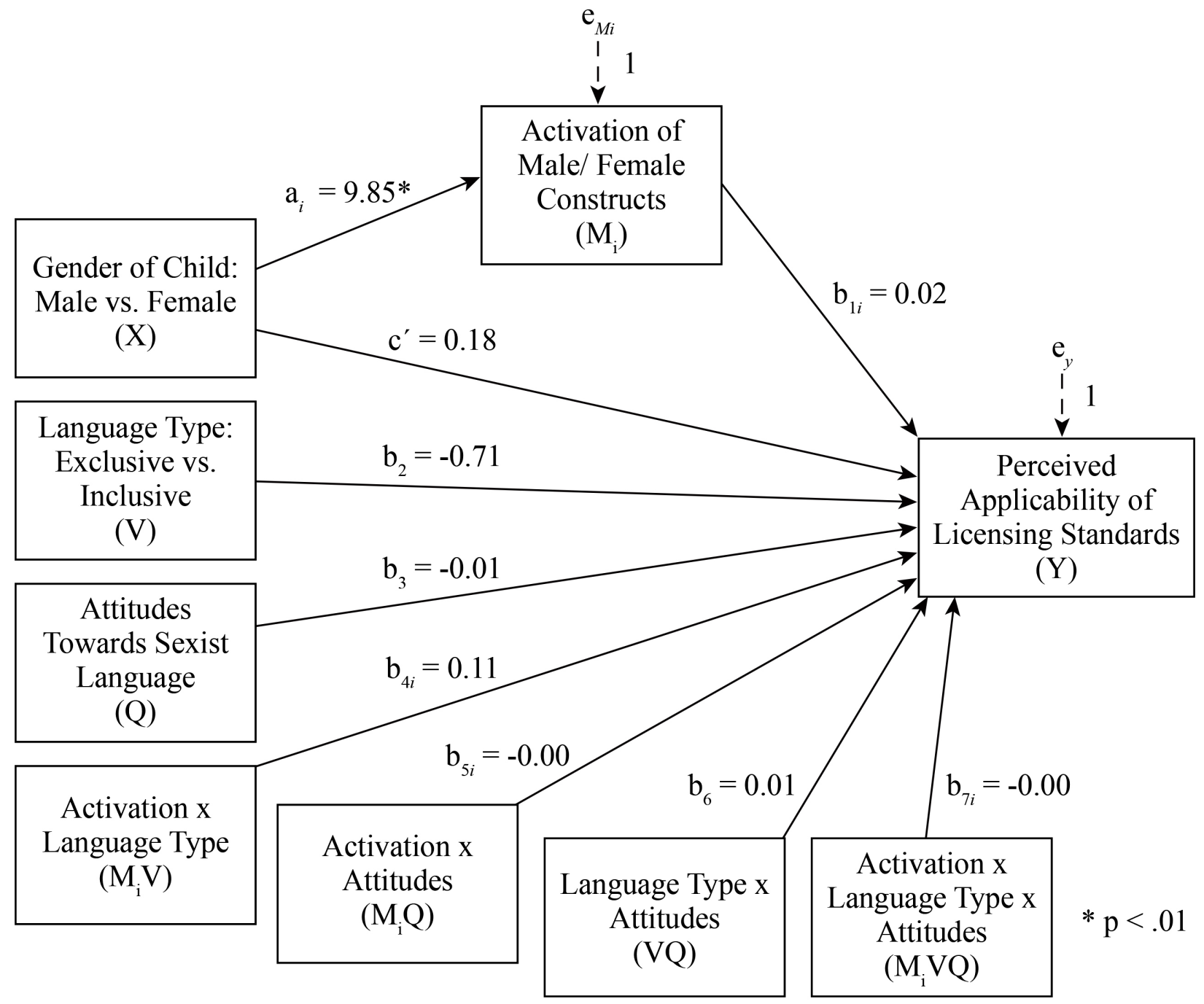

Figure 4. Statistical representation of Figure 3 with unstandardized regression paths denoted. 
Table 4

Model Coefficients for the Conditional Process Model in Figure 4

\begin{tabular}{cccccccccccc}
\hline & \multicolumn{10}{c}{$M$ (Activation of Constructs) } & \multicolumn{1}{c}{$Y$ (Perceived Applicability) } \\
Antecedent & Coeff. & $S E$ & LLCI & ULCI & & Coeff. & $S E$ & LLCI & $U L C I$ \\
\hline$X$ (Gender of Child) & $a_{i}$ & 9.85 & 0.34 & 9.19 & 10.51 & $c^{\prime}$ & 0.18 & 0.21 & -0.22 & 0.59 \\
$M$ (Activation) & - & - & - & - & $b_{1 i}$ & 0.02 & 0.06 & -0.10 & 0.14 \\
$V$ (Language Type) & - & - & - & - & $b_{2}$ & -0.71 & 0.67 & -2.03 & 0.61 \\
$Q$ (Attitudes) & - & - & - & - & $b_{3}$ & -0.01 & 0.01 & -0.03 & 0.02 \\
$M \times V$ & - & - & - & - & $b_{4 i}$ & 0.11 & 0.06 & -0.01 & 0.23 \\
$M \times Q$ & - & - & - & - & $b_{5 i}$ & -0.00 & 0.00 & -0.00 & 0.00 \\
$V \times Q$ & & & & & $b_{6}$ & 0.01 & 0.01 & -0.01 & 0.03 \\
$M \times V \times Q$ & & & & & $b_{7 i}$ & -0.00 & 0.00 & -0.00 & 0.00 \\
Constant $i_{1}$ & 0.11 & 0.34 & -0.55 & 0.77 & $i_{2}$ & 6.10 & 0.67 & 4.78 & 7.42 \\
& \multicolumn{9}{c}{$R^{2}=0.76$} \\
\end{tabular}

\section{Exploratory Analyses}

Exploratory analyses were conducted to determine whether participant characteristics such as gender, age, and education level significantly influenced any of the findings described above. No changes in significance were observed.

Further exploratory analyses were conducted to determine whether perceived aggression of the child or other variables acted as a significant mediator in the hypothetical models described above. In these analyses, participant ratings of child aggression or other potential indicators of the activation of gendered constructs (such as the number of times the child's name was used and the number of times gender-stereotyped words such as "emotional" or "aggressive" were used in participant open-ended responses) were substituted for the LIWC score. No changes in significance were observed and the models were not supported. 


\section{CHAPTER V: DISCUSSION}

\section{Overview of Findings}

This study aimed to explore whether reading gender-biased language in the LSFFH creates cognitive differences compared to those who read revisions written with gender-neutral language, whether differences in gender-biased language in the LSFFH create differences in how these standards are interpreted for boys versus girls, and whether there are specific individual differences that would influence participant responses to these questions. Based on the results described above, we cannot state any of our hypotheses were supported by statistical exploration of these questions.

Hypothesis 1 predicted that participants in the female child / exclusive language condition would be (a) more likely to determine that the legal language does not apply to female children, (b) more likely to determine that the foster parents are guilty of inappropriate use of punishment, and (c) would choose more severe corrective action to rectify the situation than those in the other three conditions. This hypothesis was not supported. Participants in the female child / exclusive language condition did not provide significantly different evaluations of applicability, determination of guilt, or severity of corrective plan compared to the other conditions.

Hypothesis 2 predicted that participants in the male child / exclusive language condition (a) would be more likely to determine that the legal language does apply to male children, (b) would be the least likely to determine that the foster parents are guilty of inappropriate use of punishment, and (c) would choose the least severe corrective action to rectify the situation, compared to the other three conditions. This hypothesis was not supported. Participants in the male child/ exclusive language condition did not evaluate the applicability of the language, guilt 
of the foster parents, or suggested corrective action significantly differently than participants in the other conditions.

Hypothesis 3 predicted that activation of gender constructs would mediate participant responses to the hypothetical scenario and subsequent interpretation of the legal language to determine its applicability to the situation at hand. This hypothesis was not supported. Stronger activation of gendered constructs did not lead to differing levels of perceived applicability of the licensing standards in our proposed moderated mediation model. Our second model incorporating attitudes towards sexist/nonsexist language did have some individual paths that approached significance, but none reached the threshold of significance, and all $95 \%$ confidence intervals straddled zero.

Finally, Hypotheses 4 and 5 predicted that attitudes towards nonsexist language and modern sexism would moderate the effects described above, with individuals who have more positive attitudes towards nonsexist language and lower levels of modern sexism being less affected by the use of gender-exclusive language. These hypotheses were not supported. Attitudes towards nonsexist language and modern sexism did not emerge as significant moderators in any of our analyses.

We are now faced with the difficult task of interpreting these analyses. As previously stated, this study failed to support all five hypotheses and no significant findings were found. Although we cannot definitely draw conclusions from nonsignificant results, there are several potential explanations for why this study failed to find any significant effects despite its theoretical foundation in previously established research literature. 


\section{Potential Design Issues}

Some of the potential explanations for our lack of significant findings can be found in looking at the descriptive data. Participant responses for applicability of the licensing standards were negatively skewed, indicating that participants tended to find the rules applicable to the situation regardless of condition. Responses were positively skewed for corrective plan, with participants tending to choose the least severe corrective action or indicating that no corrective action was needed at all. In all, three-fourths of the participants decided that the foster parents were not guilty of inappropriate use of punishment, regardless of condition. These patterns indicate that most of our sample, regardless of condition, seemed to think that the foster parents' actions were legal, based on the legal language provided.

This could be interpreted in several different ways. One of the most likely explanations is flawed design; this study may have provided a weaker manipulation compared to previous studies demonstrating a language effect. Previous research (e.g., Bem \& Bem, 1973; Hamilton, Hunter, \& Stuart-Smith, 2012; McConnell \& Fazio, 1996) has shown providing participants with gender-biased language leads to subsequent differential interpretation of the language for men versus women, but no significant effects were found based on language type whatsoever in this study. Our moderated mediation model showed that the gender of the child was salient enough to prime differential activation of male and female constructs for those in the male child and female child conditions, respectively. This is promising in that it appears that our gendered prime was successful; however, this is where our significant findings end. There was no manipulation check in this design to determine whether the legal language prime was extensive enough to manipulate participant responses. Previous research has varied in its methodology, but many studies (such as Bem and Bem's method of providing participants with full job descriptions) were more extensive 
in the types of primes they provided to participants in terms of the gender-biased (vs. genderneutral) language provided.

It should also be noted that asking participants who are not familiar with the foster care system to interpret legal language governing the treatment of children is a relatively foreign task; it would be expected that many, if not all, of our participants had never had to complete this type of task before. It is possible that the language prime we used may be sufficient for studies of lower-level language processing, but that it was not salient enough to demonstrate effects for such a novel task. Perhaps if this study were repeated with a stronger manipulation to reinforce the type of legal language used, participant responses would have been quite different.

\section{Theoretical Issues}

In addition to novelty of the task with regards to asking participants to interpret legal language for foster care, our manipulation was also novel in that we asked participants to interpret language that governed the behavior of children. To the best of our knowledge, all previous research regarding the effects of gender-biased language has either investigated the effects of gender-biased language as it pertains to adults or examined the effects of gender-biased language on children's thought processes (Conkright, Flannagan, \& Dykes, 2000; Hyde, 1984). We are not aware of any previous research that examines how adults might interpret genderbiased language that is written about children. It is possible that gender-biased language creates less of a bias when it is interpreted for children than when it is used to govern adult behavior; this possibility should be explored with further research.

Another possibility is that there are different stereotypes coming into play in this study that are conflicting with the interpretation of the gender-exclusive language. For example, several participants commented on the plight of children in foster care in the United States; it 
was clear at least some of these individuals had preconceptions of how a foster child might act. Stereotypes of foster care and of foster children may have overridden other possible interpretations of the scenario, such that these types of stereotypes influenced the judgment of the situation more than the legal language did. For example, it may be that we expect foster children to have behavioral problems and/or behave aggressively, which could be why participants were more likely to indicate that the foster parents were following the legal language dictating that children could be restrained if they were posing a threat to themselves or others.

\section{Other Methodological Issues}

Other findings from this study also warrant further examination. Reliability for the IASNL-G was lower than expected $(\alpha=.67)$, and it is unclear why this was so. There was also a main effect of MSS-Old-Fashioned Sexism, such that participants higher in Old-Fashioned Sexism tended to find the licensing standards less applicable, were more likely to find the foster

parents guilty of inappropriate use of punishment, and tended to choose more severe corrective plans than those lower in Old-Fashioned Sexism. Previous research has found significant relationships between sexism and right-wing authoritarianism (RWA), which is a worldview that favors convention and conservatism and respects punitive consequences (Akrami, Ekehammar, \& Yang-Wallentin, 2011; Begany \& Milburn, 2002; Nicol \& Rounding, 2013). This relationship between sexism and authoritarianism could explain why participants who scored higher in OldFashioned Sexism were more likely to choose punitive consequences for the individuals in question, although it would not explain why these participants also tended to find the licensing standards less applicable. Further research should be conducted in this area to determine if RWA or other forms of traditionalism or conservatism influence these results. 
Another possible explanation for our nonsignificant findings lies in the sampling methods used for this study. Our research used participants that were older on average, with the mean participant age being $34.91(S D=11.65)$ years. Our sample was also predominantly well educated, with $52.6 \%$ of individuals having completed a college degree or higher and an additional $36.9 \%$ having completed some college. This is substantially older and more educated than what is typically collected in psychology research, which tends to consist of college-age individuals recruited from introductory psychology course pools. It may be that gender-biased language apologists are correct, and that with age and education we learn to read gender-biased language as intending to include both men and women. This possibility is supported by the significant positive correlations we found between age and perceived aggression of the child, as well as between age and perceived applicability of the licensing standards. Although these correlations were not substantial enough to significantly influence our moderated mediation models, these relationships warrant exploration in further study.

This study also employed online research methods, with participants completing the survey remotely on Amazon's Mechanical Turk. The majority of previous research conducted on this topic has been in-person studies, with participants completing surveys or tasks in a lab or a classroom. It could be that performing tasks in the lab adds a layer of social desirability, causing more participants to interpret gender-biased language through a more "politically correct" lens and exacerbating the effect of using gender-biased versus gender-neutral language. Further research on this topic using online methods should be explored to elucidate these findings.

\section{Strengths}

Despite nonsignificant findings, this research does possess several strengths. One major strength of this experiment is external validity; the procedure followed by participants in this 
study strongly mirrors the procedure undertaken by child welfare personnel across the state of Illinois. These individuals are asked to evaluate situations experienced by foster children every day and interpret them though the lens of legal language that is, in many sections, written with gender-exclusive language. It is important that this issue continue to be explored to determine whether the use of gender-exclusive language has real-life implications for how children are being treated in foster care.

Another strength of this study is that we attempted integrate a moderated mediation model to explain a previously demonstrated effect. Many studies have found that manipulating language to either be gender-exclusive or gender-inclusive creates changes in how individuals visualize others and interpret the meaning of the language. However, while many have proposed theoretical explanations of these effects, few studies have attempted to explain the underlying mechanisms of these effects through statistical analysis. This study is an important first step in exploring how gender-biased language affects our cognition, imagery, and subsequent interpretation. This is especially important in that our second proposed moderated mediation model approached significance for many of the regression paths. An excellent next step to follow up from this study would be to perform an empirical power estimation for this type of moderated mediation model. This would help ensure that this study was sufficiently powered for the complex models that were hypothesized and help guide subsequent studies in terms of sampling.

\section{Conclusion}

In sum, further refinement of these manipulations is needed in order to explore this issue. Additional research is required to determine what types of stereotypes exist about the foster care system in the United States and whether these preconceptions may influence other types of judgments made about youth in care. Further research should also be done to explore whether 
gender-biased language is interpreted differently when children are the subject in question, rather than adults. Nonetheless, this experiment is an important first step in determining what effect, if any, the use of gender-exclusive language exerts in the domain of foster care in Illinois. Further research should be conducted to determine whether gender-exclusive language in legal language has an effect on the treatment of foster children - and if so, under what conditions these effects may be mitigated. 


\section{REFERENCES}

Akrami, N., Ekehammar, B., \& Yang-Wallentin, F. (2011). Personality and social psychology factors explaining sexism. Journal of Individual Differences, 32, 153-160. doi: $10.1027 / 1614-0001 / \mathrm{a} 000043$

APA Publication Manual Task Force (1977). Guidelines for non-sexist language in APA journals: Publication Manual change sheet 2. American Psychologist, 32, 487-494.

Bem, S.L., \& Bem, D. J. (1973). Does sex-biased job advertising "aid and abet” sex discrimination? Journal of Applied Social Psychology, 3, 6-18. doi: 10.1111/j.15591816.1973.tb01290.x.

Begany, J. J., \& Milburn, M. A. (2002). Psychological predictors of sexual harassment: Authoritarianism, hostile sexism, and rape myths. Psychology of Men \& Masculinity, 3, 119-126. doi: 10.1037//1524-9220.3.2.119

Bodine, A. (1975). Androcentrism in prescriptive grammar: Singular "they," sex-indefinite "he" and "he or she." Language in Society, 4, 129-146.

Boroditsky, L. (2009). How does our language shape the way we think? In M. Brockman (Ed.), What's next? Dispatches on the future of science (pp. 116-129). New York, NY: Vintage.

Boroditsky, L., Schmidt, L. A., \& Phillips, W. (2003). Sex, syntax, and semantics. In D. Gentner \& S. Goldin-Meadow (Eds.), Language in mind: Advances in the study of language and cognition (pp. 61-79). Cambridge, MA: MIT.

Campbell, B., Schellenberg, E. G., \& Senn, C. Y. (1997). Evaluating measures of contemporary sexism. Psychology of Women Quarterly, 21, 89-102. 
Child Care Act of 1969, P.A. 76-63, 225 ILCS $10 \S 23$ (1969). Accessed at http://www.ilga.gov/legislation/ilcs/ilcs3.asp?ActID=1293.

Cole, C. M., Hill, F. A., \& Dayley, L. J. (1983). Do masculine pronouns used generically lead to thoughts of men? Sex Roles, 9, 737-750.

Conkright, L., Flannagan, D., \& Dykes, J. (2000). Effects of pronoun type and gender role consistency on children's recall and interpretation of stories. Sex Roles, 43(7-8), 481497.

Eagly, A. H., \& Kite, M. E. (1987). Are stereotypes of nationalities applied to both women and men? Journal of Personality and Social Psychology, 53, 451-62.

Foley, T., \& Safran, S. P. (1994). Gender-biased language in learning disability textbooks. Journal of Learning Disabilities, 27, 309-314.

Formanowicz, M., Bedynska, S., Cislak, A., Braun, F., \& Sczesny, S. (2013). Side effects of gender-fair language: How feminine job titles influence the evaluation of female applicants. European Journal of Social Psychology, 43, 62-71. doi: 10.1002/ejsp.1924

Garnham, A., Gabriel., U., Sarrasin, O., Gygax, P., \& Oakhill, J. (2012). Gender representation in different languages and grammatical marking on pronouns: When beauticians, musicians, and mechanics remain men. Discourse Processes, 49, 481-500. doi: $10.1080 / 0163853 X .2012 .688184$

Gastil, J. (1990). Generic pronouns and sexist language: The oxymoronic character of masculine generics. Sex Roles, 23, 629-643.

Gentner, D., \& Goldin-Meadow, S. (2003). Whither Whorf. In D. Gentner \& S. GoldinMeadow (Eds.), Language in mind: Advances in the study of language and cognition ( $\mathrm{p}$. 3-15). Cambridge, MA: MIT. 
Hamilton, M. C. (1988). Using masculine generics: Does generic he increase male bias in the user's imagery? Sex Roles, 19, 785-99.

Hamilton, M.C., Hunter, B., \& Stuart-Smith, S. (1992) Jury instructions worded in the masculine generic: can a woman claim self-defense when "he" is threatened? In J.C. Chrisler, D. Howard, (Eds.), New Directions in Feminist Psychology: Practice, Theory, and Research. New York: Springer.

Harper \& Row Publishers, Inc. (1976). Harper and Row guidelines on equal treatment of the sexes in textbooks. New York: Author.

Hayes, A. F. (2013). Introduction to mediation, moderation, and conditional process analysis: A regression-based approach. New York: Guilford Press.

Hayes, A. F. (2015). An index and test of linear moderated mediation. Multivariate Behavioral Research, 50(1), 1-22.

Hegarty, P., \& Buechel, C. (2006). Androcentric reporting of gender differences in APA journals: 1965-2004. Review of General Psychology, 10, 377-389. doi: $10.1037 / 1089-2680.10 .4 .377$

Hellinger, M., \& Bußmann, H. (2001). The linguistic representation of women and men. In M. Hellinger \& H. Bußmann (Eds.), Gender across languages (Vol. 1, pp. 1-25). Philadelphia: John Benjamins Company.

Higgins, E. T., Rholes, W. S., \& Jones, C. R. (1977). Category accessibility and impression formation. Journal of Experimental Social Psychology, 13, 141-154.

Hitlan, R. T., Pryor, J. B., Hesson-McInnis, M. S., \& Olson, M. (2009). Antecedents of gender harassment: An analysis of person and situation factors. Sex Roles, 61, 794-807. 
Holt, Rinehart \& Winston (College Division). (1976). The treatment of sex roles and minorities. New York: Author.

Hussein, B. A. (2012). The Sapir-Whorf hypothesis today. Theory and Practice in Language Studies, 2(3), 642-6. doi: 10.4304/tpls.2.3.642-646

Hyde, J. S. (1984). Children's understanding of sexist language. Developmental Psychology, 20, 697-706.

Illinois General Assembly Joint Committee on Administrative Rules. Licensing Standards for Foster Family Homes (March 5, 2012). Title 89, Chapter III, Subchapter E, Part 402. Available from: http://www.ilga.gov/commission/jcar/ admincode/089/08900402sections.html; Accessed: 9/1/2015.

Illinois General Assembly Joint Committee on Administrative Rules. Licensing Enforcement (September 27, 2012). Title 89, Chapter III, Subchapter D, Part 383. Available from https://www.illinois.gov/dcfs/aboutus/notices/Documents/rules_383.pdf; Accessed: 4/3/2016.

John Wiley \& Sons, Inc. (1977). Wiley guidelines on sexism in language. New York: Author.

Khan, M., \& Daneman, M. (2011). How readers spontaneously interpret man-suffix words: Evidence from eye movements. Journal of Psycholinguistic Research, 40, 351366. doi: 10.1007/s10936-011-9173-3

Khosroshahi, F. (1989). Penguins don't care, but women do: A social identity analysis of a Whorfian problem. Language in Society, 18, 505-525.

Lassonde, K. A., \& O’Brien, E. J. (2013). Occupational stereotypes: Activation of male bias in a gender-neutral world. Journal of Applied Social Psychology, 43, 387-396. doi: 10.1111/j.1559-1816.2013.01008.x 
Maass, A. (1999). Linguistic intergroup bias: Stereotype perpetuation through language. In M. P. Zanna (Ed.), Advances in experimental social psychology (Vol. 31, p. 79-121). San Diego, CA: Academic Press.

MacKay, D. G. (1980). Psychology, prescriptive grammar, and the pronoun problem. American Psychologist, 35, 444-449.

Madson, L., \& Hessling, R. M. (1999). Does alternating between masculine and feminine pronouns eliminate perceived gender bias in text? Sex Roles, 41(7-8), 559-575.

Madson, L., \& Shoda, J. (2006). Alternating between masculine and feminine pronouns: Does essay topic affect readers' perceptions? Sex Roles, 54, 275-285. doi: 10.1007/s11199006-9344-0

Martyna, W. (1980). Beyond the "he/man" approach: The case for nonsexist language. Signs, 5, 482-493.

McConnell, A. R., \& Fazio, R. H. (1996). Women as men and people: Effects of gendermarked language. Personality and Social Psychology Bulletin, 22, 1004-13.

Merritt, R., D., \& Kok, C. J. (1997). Implications of the People=Male Theory for the interpretation of the Draw-A-Person Test. Journal of Personality Assessment, 68, 211214.

Miller, M. M., \& James, L. E., (2009). Is the generic pronoun he still comprehended as excluding women? The American Journal of Psychology, 122, 483-96.

Moser, F., \& Hannover, B. (2014). How gender-fair are schoolbooks in Germany in the 21st century? An analysis of language and illustrations in schoolbooks for mathematics and German. European Journal of Psychology of Education, 29, 387-407. 
Moulton, J., Robinson, G. M., \& Elias, C. (1978). Sex bias in language use: "Neutral” pronouns that aren't. American Psychologist, 33, 1032-1036.

Nicol, A. A. M., \& Rounding, K. (2013). Alienation and empathy as mediators of the relation between Social Dominance Orientation, Right-Wing Authoritarianism and expressions of racism and sexism. Personality and Individual Differences, 55, 294-299. http://dx.doi.org/10.1016/j.paid.2013.03.009

Parks, J. B., \& Roberton, M. A. (2000). Development and validation of an instrument to measure attitudes toward sexist/nonsexist language. Sex Roles, 42, 415-438.

Parks, J. B., \& Roberton, M. A. (2004). Attitudes toward women mediate the gender effect on attitudes toward sexist language. Psychology of Women Quarterly, 28, 233-239.

Parks, J. B., \& Roberton, M. A. (2005). Explaining age and gender effects on attitudes toward sexist language. Journal of Language and Social Psychology, 24, 401-411.

Pennebaker, J. W., Booth, R. J., Boyd, R. L., \& Francis, M. E. (2015). Linguistic Inquiry and Word Count: LIWC2015. Austin, TX: Pennebaker Conglomerates. (www.LIWC.net).

Prewitt-Freilino, J. L., Caswell, T. A., \& Laakso, E. K. (2012). The gendering of language: A comparison of gender equality in countries with gendered, natural gender, and genderless languages. Sex Roles, 66, 268-281. doi: 10.1007/s11199-011-0083-5

Rose, L. M. (2010). The Supreme Court and gender-neutral language: Setting the standard or lagging behind? Duke Journal of Gender Law and Policy, 81-129.

Sarrasin, O., Gabriel, U., \& Gygax, P. (2012). Sexism and attitudes toward genderneutral language: The case of English, French, and German. Swiss Journal of Psychology, 71(3), 113-124. 
Schneider, J. W., \& Hacker, S. L. (1973). Sex role imagery and use of the generic "man" in introductory texts: A case in the sociology of sociology. American Sociologist, $8,12-18$

Semin, G. R., \& Fiedler, K. (Eds.). (1992). Language, interaction, and social cognition. London: Sage Publications.

Sendén, M. G., Sikström, S., \& Lindholm, T. (2015). "She" and "he" in news media messages: Pronoun use reflects gender biases in semantic contexts. Sex Roles, 72, 40-49. doi: 10.1007/s11199-014-0437-x

Silveira, J. (1980). Generic masculine words and thinking. Women's Studies International Quarterly, 3, 165-178.

Smith, C. A., Johnston-Robledo, I., McHugh, M. C., \& Chrisler, J. C. (2010). Words matter: The language of gender. In J. C. Chrisler \& D. R. McCreary (Eds.), Handbook of gender research in psychology (Vol. 1, pp. 361-378). New York, NY: Springer.

Stahlberg, D., Braun, F., Irmen, L., \& Sczesny, S. (2007). Representation of the sexes in language. In K. Fiedler (Ed.), Social communication (p. 163-187). New York, NY: Psychology Press.

Stahlberg, D., Sczesny, S., \& Braun, F. (2001). Name your favorite musician: Effects of masculine generics and of their alternatives in German. Journal of Language and Social Psychology, 20, 464-469.

Stout, J. G., \& Dasgupta, N. (2011). When he doesn't mean you: Gender-exclusive language as ostracism. Personality and Social Psychology Bulletin, 36, 757-769. doi: $10.1177 / 0146167211406434$ 
Swim, J. K., Aikin, K. J., Hall, W. S., \& Hunter, B. A. (1995). Sexism and racism: Old-fashioned and modern prejudices. Journal of Personality and Social Psychology, 68, 199-214.

Swim, J. K., Mallett, R., Russo-Devosa, Y., \& Stangor, C. (2005). Judgments of sexism: A comparison of the subtlety of sexism measures and sources of variability in judgments of sexism. Psychology of Women Quarterly, 29, 406-411.

Tausczik, Y. R., \& Pennebaker, J. W. (2010). The psychological meaning of words: LIWC and computerized text analysis methods. Journal of Language and Social Psychology, 29, 24-54.

Tougas, F., Brown, R., Beaton, A. M., \& Joly, S. (1995). Neosexism: Plus ça change, plus c'est pareil. Personality and Social Psychology Bulletin, 21, 842-849.

Vervecken, D., \& Hannover, B. (2012). Ambassadors of gender equality? How use of pair forms versus masculines as generics impacts perception of the speaker. European Journal of Social Psychology, 42, 754-762. doi: 10.1002/ejsp.1893

Vervecken, D., \& Hannover, B. (2015). Yes I can! Effects of gender fair job descriptions on children's perceptions of job status, job difficulty, and vocational self-efficacy. Social Psychology, 46, 76-92. doi: 10.1027/1864-9335/a000229

Vervecken, D., Hannover, B., \& Wolter, I. (2013). Changing (s)expectations: How gender fair job descriptions impact children's perceptions and interest regarding traditionally male occupations. Journal of Vocational Behavior, 82, 208-220. doi: 10.1016/j.jvb.2013.01.008

Wasserman, B. D., \& Weseley, A. J. (2009). ¿Qué? Quoi? Do languages with grammatical gender promote sexist attitudes? Sex Roles, 61, 634-43. doi: 10.1007/s $11199-009-9696-3$ 
Wigboldus, D., \& Douglas, K. (2007). Language, stereotypes, and intergroup relations. In K. Fiedler (Ed.), Social communication (p. 107-128). New York, NY: Psychology Press.

Wilson, E., \& Ng, S. H. (1988). Sex bias in visual images evoked by generics: A New Zealand study. Sex Roles, 18, 159-168. 


\section{APPENDIX A: SURVEY MATERIALS}

\section{Condition 1: Male Child/Gender-Exclusive Language}

\section{Part 1: Introduction}

Foster children are defined as individuals under the age of 18 who have been removed from their biological parents, usually as a result of a court order or intervention by local child welfare services, and placed with an individual or family to be cared for. In the state of Illinois, the treatment of foster children by their foster parents is regulated by rules set forth in Title 90.III.e, Part 402, Licensing Standards for Foster Family Homes. We are trying to determine whether the current wording in these rules is clear and understandable enough to guarantee that foster children are kept safe and treated fairly in foster homes.

Imagine you are an individual who has been charged with evaluating allegations of misconduct in the foster care system. In this task, you will read about a situation where foster parents may have broken one or more of the rules governing the treatment of foster children placed in their home. Your job is to interpret the rules given and decide whether the foster parents acted inappropriately. If you decide that a rule was broken, you will then be asked to choose what an appropriate punishment might be for this situation. 


\section{Part 2: Read and Respond}

The following is an example of an event experienced by a foster child. Please read the description carefully and then use it to answer the questions that follow.

James is an 11-year-old boy who is currently placed in foster care. He has been living in his current foster home for about 6 months. James has a history of behavioral issues, and he often acts out when he does not get his way. The other day, James had a tantrum when he was not allowed to watch TV. He began screaming and throwing his possessions around his room. James' foster parents pinned him to the floor (i.e., held down his hands and feet) until he calmed down and agreed to sit in time-out.

What is your general impression of James? Please provide your answer in the box below using at least 3 sentences.

Do you think James was behaving aggressively?

$1-$ No, not at all

2

3

4

5

6

7 - Yes, definitely

The foster parents described in this situation were reported to foster care authorities by a neighbor.

Your job is to decide whether the foster parents broke the foster care rules.

The following excerpt describes some of the rules governing the treatment of children in foster care:

1) Each child shall have the opportunity to learn to assume some responsibility for himself and for household duties in accordance with his age, health, and ability. No child shall be permitted to do tasks which are hazardous, dangerous or risk harm to the child.

2) No child shall be subjected to corporal punishment, verbal abuse, threats or derogatory remarks about him or his family.

3) A child may be temporarily restrained by a person physically holding the child if the child poses a danger to himself or to others.

4) The personal spending money of a child may be used as a constructive disciplinary 
measure to teach the child about responsibility and the consequences of his behavior. However, no more than $\mathbf{5 0 \%}$ of the child's monthly personal spending money shall be withheld for any reason.

5) All personal or identifying information concerning a foster child, including but not limited to, his background, his family, and the identity and location of all other persons or families with whom he has been, or will be placed, shall be treated as confidential by all persons involved with the child.

Do you think the guidelines described here are directly applicable to what happened to James?

$1-$ No, not at all

2

3

4

5

6

7 - Yes, definitely

Based on the guidelines described above, do you think James' foster parents are guilty of inappropriate use of discipline?

Yes

No

What type of corrective action do you think James' foster parents should receive for this incident?

These foster parents did not break any rules; therefore, no corrective action is needed.

They should receive only a verbal warning.

- They should receive a written warning that is placed on their permanent record.

— They should receive a written warning AND undergo more training about how to appropriately discipline foster children.

They should receive a written warning, undergo more training, AND the child should be removed from their home.

_ They should lose their foster care license.

— They should lose their foster care license AND be charged with child abuse.

_ Other, please specify:

Any additional comments about this scenario (optional): 


\section{Part 3: Attitudes Toward Sexist/Nonsexist Language Questionnaire}

We would like to ask you a few questions about how you interpret different types of language.

Please use the following definition in completing this questionnaire: Sexist language includes words, phrases, and expressions that unnecessarily differentiate between females and males or exclude, trivialize, or diminish either gender.

SECTION I: For each of the following expressions, choose the descriptor that most closely corresponds with your beliefs about language.

\begin{tabular}{|c|c|c|c|c|}
\hline $\begin{array}{l}\text { Strongly } \\
\text { Disagree }\end{array}$ & $\begin{array}{l}\text { Tend to } \\
\text { Disagree }\end{array}$ & Undecided & $\begin{array}{l}\text { Tend to } \\
\text { Agree }\end{array}$ & $\begin{array}{l}\text { Strongly } \\
\text { Agree }\end{array}$ \\
\hline 1-------- & ----- & $--3-$ & --4------. & ---5 \\
\hline
\end{tabular}

1. Women who think that being called a "chairman" is sexist are misinterpreting the word "chairman."

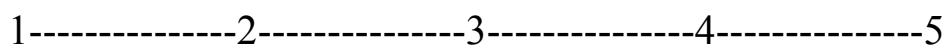

2. We should not change the way the English language has traditionally been written and spoken.

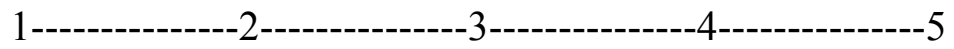

3. Worrying about sexist language is a trivial activity.

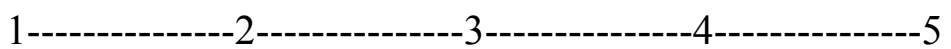

4. If the original meaning of the word "he" was "person," we should continue to use "he" to refer to both males and females today.

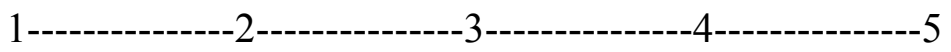
5 . When people use the term "man and wife," the expression is not sexist if the users don't mean it to be. 1 6 . The English language will never be changed because it is too deeply ingrained in the culture.

7. The elimination of sexist language is an important goal. 8. Most publication guidelines require newspaper writers to avoid using ethnic and racial slurs. So, these guidelines should also require writers to avoid sexist language.
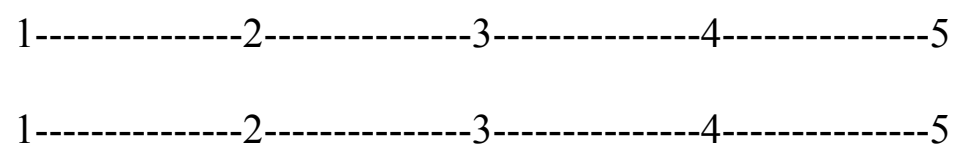
9. Sexist language is related to sexist treatment of people in society. 10. When teachers talk about the history of the United States, they should change expressions, such as "our forefathers," to expressions 
that include women.

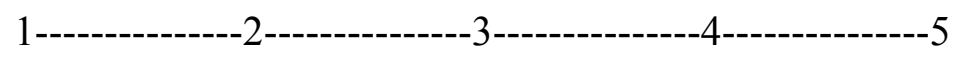

11. Teachers who require students

to use nonsexist language are

unfairly forcing their political

views upon their students.

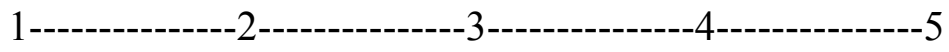

12. Although change is difficult, we still should try to eliminate

sexist language.

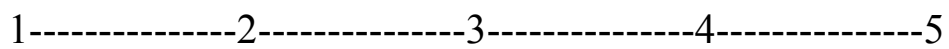

SECTION II: Are the underlined words and phrases in the following sentences sexist?

$1=$ not at all sexist; $2=$ probably not sexist; $3=$ undecided; $4=$ somewhat sexist; $5=$ definitely sexist

13. People should care about all mankind, not just themselves.

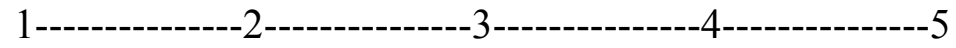

14. The belief that frogs will give you warts is just an old wives' tale.

15. If a child wants to play the piano well, he must practice hard.

$$
1
$$

16. Alice Jones should be chairman

of our committee.

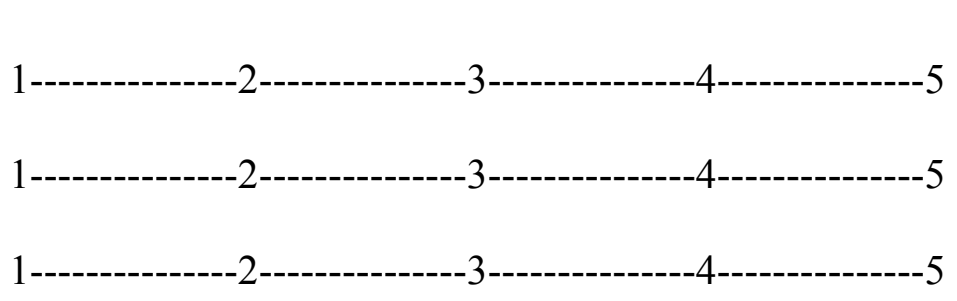

SECTION III: Choose the descriptor that most closely describes you in the following situations. $1=$ very unwilling; $2=$ reluctant; $3=$ undecided; $4=$ somewhat willing; $5=$ very willing

17. When you are referring to a

married woman, how willing are you

to use the title "Ms. Smith"

rather than "Mrs. Smith"?

1-----------------2-----------------3-----------------4-----------------5

18. How willing are you to use the word "server" rather than "waiter" or "waitress"?

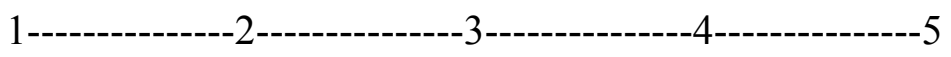

19. How willing are you to use the expression "husband and wife" rather than "man and wife"?

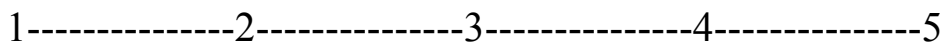

20. How willing are you to use the term "camera operator" rather than "cameraman"?

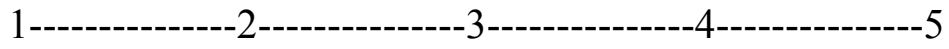

21. How willing are you to use the title "flight attendant" instead of "steward" or "stewardess"?

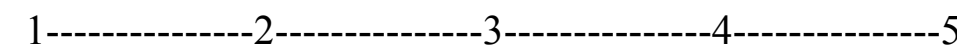

\section{Reminder: Sexist language includes words, phrases, and expressions that unnecessarily differentiate between females and males or exclude, trivialize, or diminish either gender.}




\section{Part 4: Demographics}

Now we would like to ask you some basic questions about yourself.

1. What is your gender?

2. What is your age?

3. What is your highest level of education?

4. Describe your race or ethnic background. 


\section{Condition 2: Male Child/Gender-Inclusive Language}

\section{Part 1: Introduction}

Foster children are defined as individuals under the age of 18 who have been removed from their biological parents, usually as a result of a court order or intervention by local child welfare services, and placed with an individual or family to be cared for. In the state of Illinois, the treatment of foster children by their foster parents is regulated by rules set forth in Title 90.III.e, Part 402, Licensing Standards for Foster Family Homes. We are trying to determine whether the current wording in these rules is clear and understandable enough to guarantee that foster children are kept safe and treated fairly in foster homes.

Imagine you are an individual who has been charged with evaluating allegations of misconduct in the foster care system. In this task, you will read about a situation where foster parents may have broken one or more of the rules governing the treatment of foster children placed in their home. Your job is to interpret the rules given and decide whether the foster parents acted inappropriately. If you decide that a rule was broken, you will then be asked to choose what an appropriate punishment might be for this situation. 


\section{Part 2: Read and Respond}

The following is an example of an event experienced by a foster child. Please read the description carefully and then use it to answer the questions that follow.

James is an 11-year-old boy who is currently placed in foster care. He has been living in his current foster home for about 6 months. James has a history of behavioral issues, and he often acts out when he does not get his way. The other day, James had a tantrum when he was not allowed to watch TV. He began screaming and throwing his possessions around his room. James' foster parents pinned him to the floor (i.e., held down his hands and feet) until he calmed down and agreed to sit in time-out.

What is your general impression of James? Please provide your answer in the box below using at least 3 sentences.

Do you think James was behaving aggressively?

$1-$ No, not at all

2

3

4

5

6

7 - Yes, definitely

The foster parents described in this situation were reported to foster care authorities by a neighbor.

Your job is to decide whether the foster parents broke the foster care rules.

The following excerpt describes some of the rules governing the treatment of children in foster care:

1) Each child shall have the opportunity to learn to assume some responsibility for himself/herself and for household duties in accordance with his/her age, health, and ability. No child shall be permitted to do tasks which are hazardous, dangerous or risk harm to the child.

2) No child shall be subjected to corporal punishment, verbal abuse, threats or derogatory remarks about him/her or his/her family.

3) A child may be temporarily restrained by a person physically holding the child if the child poses a danger to himself/herself or to others. 
4) The personal spending money of a child may be used as a constructive disciplinary measure to teach the child about responsibility and the consequences of his/her behavior. However, no more than $\mathbf{5 0 \%}$ of the child's monthly personal spending money shall be withheld for any reason.

5) All personal or identifying information concerning a foster child, including but not limited to, his/her background, his/her family, and the identity and location of all other persons or families with whom he/she has been, or will be placed, shall be treated as confidential by all persons involved with the child.

Do you think the guidelines described here are directly applicable to what happened to James?

$1-$ No, not at all

2

3

4

5

6

7 - Yes, definitely

Based on the guidelines described above, do you think James' foster parents are guilty of inappropriate use of discipline?

Yes

No

What type of corrective action do you think James' foster parents should receive for this incident?

These foster parents did not break any rules; therefore, no corrective action is needed.

They should receive only a verbal warning.

- They should receive a written warning that is placed on their permanent record.

— They should receive a written warning AND undergo more training about how to appropriately discipline foster children.

They should receive a written warning, undergo more training, AND the child should be removed from their home.

_ They should lose their foster care license.

— They should lose their foster care license AND be charged with child abuse.

_ Other, please specify:

Any additional comments about this scenario (optional): 


\section{Part 3: Attitudes Toward Sexist/Nonsexist Language Questionnaire}

We would like to ask you a few questions about how you interpret different types of language.

Please use the following definition in completing this questionnaire: Sexist language includes words, phrases, and expressions that unnecessarily differentiate between females and males or exclude, trivialize, or diminish either gender.

SECTION I: For each of the following expressions, choose the descriptor that most closely corresponds with your beliefs about language.

\begin{tabular}{|c|c|c|c|c|}
\hline $\begin{array}{l}\text { Strongly } \\
\text { Disagree }\end{array}$ & $\begin{array}{l}\text { Tend to } \\
\text { Disagree }\end{array}$ & Undecided & $\begin{array}{l}\text { Tend to } \\
\text { Agree }\end{array}$ & $\begin{array}{l}\text { Strongly } \\
\text { Agree }\end{array}$ \\
\hline 1-------- & ----- & $--3-$ & --4------. & ---5 \\
\hline
\end{tabular}

1. Women who think that being called a "chairman" is sexist are misinterpreting the word "chairman."

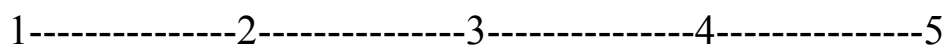

2. We should not change the way the English language has traditionally been written and spoken.

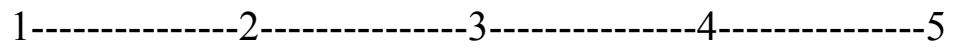

3. Worrying about sexist language is a trivial activity.

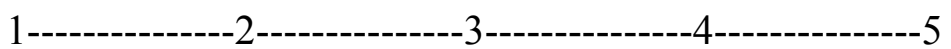

4. If the original meaning of the word "he" was "person," we should continue to use "he" to refer to both males and females today.

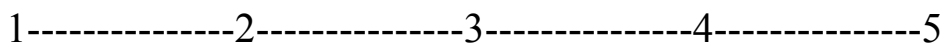
5 . When people use the term "man and wife," the expression is not sexist if the users don't mean it to be. 1 6 . The English language will never be changed because it is too deeply ingrained in the culture.

7. The elimination of sexist language is an important goal. 8. Most publication guidelines require newspaper writers to avoid using ethnic and racial slurs. So, these guidelines should also require writers to avoid sexist language.
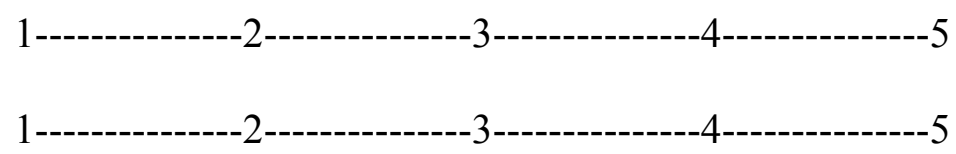
9. Sexist language is related to sexist treatment of people in society. 10. When teachers talk about the history of the United States, they should change expressions, such as "our forefathers," to expressions 
that include women.

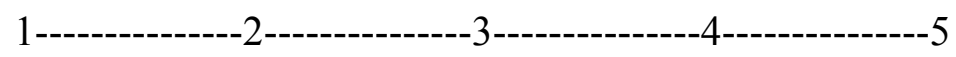

11. Teachers who require students

to use nonsexist language are

unfairly forcing their political

views upon their students.

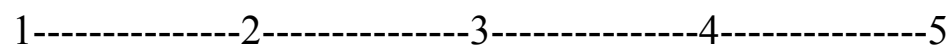

12. Although change is difficult, we still should try to eliminate

sexist language.

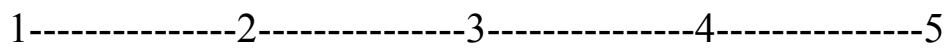

SECTION II: Are the underlined words and phrases in the following sentences sexist?

$1=$ not at all sexist; $2=$ probably not sexist; $3=$ undecided; $4=$ somewhat sexist; $5=$ definitely sexist

13. People should care about all mankind, not just themselves.

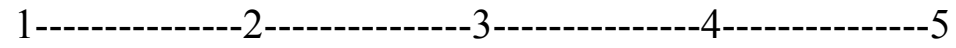

14. The belief that frogs will give you warts is just an old wives' tale.

15. If a child wants to play the piano well, he must practice hard.

$$
1
$$

16. Alice Jones should be chairman

of our committee.

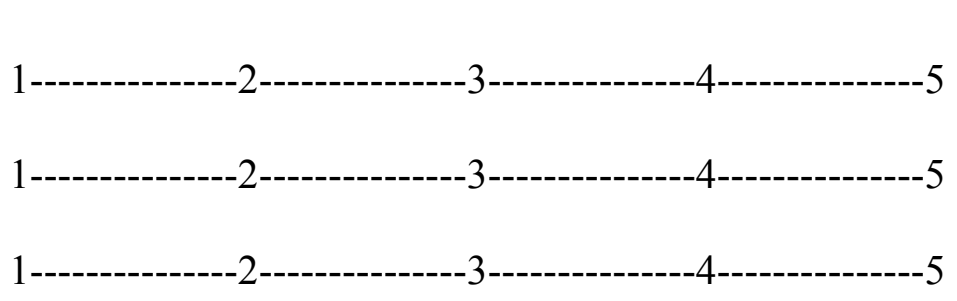

SECTION III: Choose the descriptor that most closely describes you in the following situations. $1=$ very unwilling; $2=$ reluctant; $3=$ undecided; $4=$ somewhat willing; $5=$ very willing

17. When you are referring to a

married woman, how willing are you

to use the title "Ms. Smith"

rather than "Mrs. Smith"?

1-----------------2-----------------3-----------------4-----------------5

18. How willing are you to use the word "server" rather than "waiter" or "waitress"?

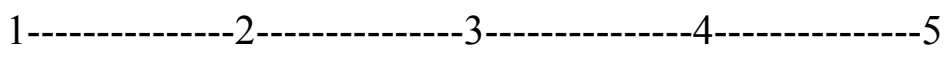

19. How willing are you to use the expression "husband and wife" rather than "man and wife"?

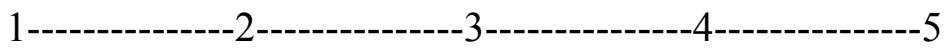

20. How willing are you to use the term "camera operator" rather than "cameraman"?

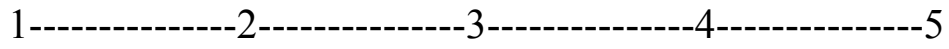

21. How willing are you to use the title "flight attendant" instead of "steward" or "stewardess"?

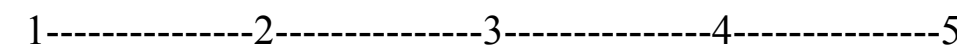

\section{Reminder: Sexist language includes words, phrases, and expressions that unnecessarily differentiate between females and males or exclude, trivialize, or diminish either gender.}




\section{Part 4: Demographics}

Now we would like to ask you some basic questions about yourself.

1. What is your gender?

2. What is your age?

3. What is your highest level of education?

4. Describe your race or ethnic background. 


\section{Condition 3: Female Child/Gender-Exclusive Language}

\section{Part 1: Introduction}

Foster children are defined as individuals under the age of 18 who have been removed from their biological parents, usually as a result of a court order or intervention by local child welfare services, and placed with an individual or family to be cared for. In the state of Illinois, the treatment of foster children by their foster parents is regulated by rules set forth in Title 90.III.e, Part 402, Licensing Standards for Foster Family Homes. We are trying to determine whether the current wording in these rules is clear and understandable enough to guarantee that foster children are kept safe and treated fairly in foster homes.

Imagine you are an individual who has been charged with evaluating allegations of misconduct in the foster care system. In this task, you will read about a situation where foster parents may have broken one or more of the rules governing the treatment of foster children placed in their home. Your job is to interpret the rules given and decide whether the foster parents acted inappropriately. If you decide that a rule was broken, you will then be asked to choose what an appropriate punishment might be for this situation. 


\section{Part 2: Read and Respond}

The following is an example of an event experienced by a foster child. Please read the description carefully and then use it to answer the questions that follow.

Jen is an 11-year-old girl who is currently placed in foster care. She has been living in her current foster home for about 6 months. Jen has a history of behavioral issues, and she often acts out when she does not get her way. The other day, Jen had a tantrum when she was not allowed to watch $\mathrm{TV}$. She began screaming and throwing her possessions around her room. Jen's foster parents pinned her to the floor (i.e., held down her hands and feet) until she calmed down and agreed to sit in time-out.

What is your general impression of Jen? Please provide your answer in the box below using at least 3 sentences.

Do you think Jen was behaving aggressively?

$1-$ No, not at all

2

3

4

5

6

7 - Yes, definitely

The foster parents described in this situation were reported to foster care authorities by a neighbor.

Your job is to decide whether the foster parents broke the foster care rules.

The following excerpt describes some of the rules governing the treatment of children in foster care:

1) Each child shall have the opportunity to learn to assume some responsibility for himself and for household duties in accordance with his age, health, and ability. No child shall be permitted to do tasks which are hazardous, dangerous or risk harm to the child.

2) No child shall be subjected to corporal punishment, verbal abuse, threats or derogatory remarks about him or his family.

3) A child may be temporarily restrained by a person physically holding the child if the child poses a danger to himself or to others.

4) The personal spending money of a child may be used as a constructive disciplinary 
measure to teach the child about responsibility and the consequences of his behavior. However, no more than $\mathbf{5 0 \%}$ of the child's monthly personal spending money shall be withheld for any reason.

5) All personal or identifying information concerning a foster child, including but not limited to, his background, his family, and the identity and location of all other persons or families with whom he has been, or will be placed, shall be treated as confidential by all persons involved with the child.

Do you think the guidelines described here are directly applicable to what happened to Jen?

$1-$ No, not at all

2

3

4

5

6

7 - Yes, definitely

Based on the guidelines described above, do you think Jen's foster parents are guilty of inappropriate use of discipline?

Yes

No

What type of corrective action do you think Jen's foster parents should receive for this incident?

These foster parents did not break any rules; therefore, no corrective action is needed.

They should receive only a verbal warning.

They should receive a written warning that is placed on their permanent record.

They should receive a written warning AND undergo more training about how to

appropriately discipline foster children.

They should receive a written warning, undergo more training, AND the child should be removed from their home.

They should lose their foster care license.

- They should lose their foster care license AND be charged with child abuse.

_ Other, please specify:

Any additional comments about this scenario (optional): 


\section{Part 3: Attitudes Toward Sexist/Nonsexist Language Questionnaire}

We would like to ask you a few questions about how you interpret different types of language.

Please use the following definition in completing this questionnaire: Sexist language includes words, phrases, and expressions that unnecessarily differentiate between females and males or exclude, trivialize, or diminish either gender.

SECTION I: For each of the following expressions, choose the descriptor that most closely corresponds with your beliefs about language.

\begin{tabular}{|c|c|c|c|c|}
\hline $\begin{array}{l}\text { Strongly } \\
\text { Disagree }\end{array}$ & $\begin{array}{l}\text { Tend to } \\
\text { Disagree }\end{array}$ & Undecided & $\begin{array}{l}\text { Tend to } \\
\text { Agree }\end{array}$ & $\begin{array}{l}\text { Strongly } \\
\text { Agree }\end{array}$ \\
\hline 1-------- & ----- & $--3-$ & --4------. & ---5 \\
\hline
\end{tabular}

1. Women who think that being called a "chairman" is sexist are misinterpreting the word "chairman."

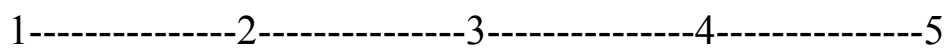

2. We should not change the way the English language has traditionally been written and spoken.

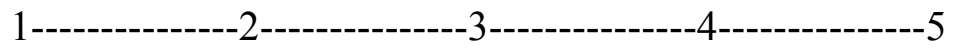

3. Worrying about sexist language is a trivial activity.

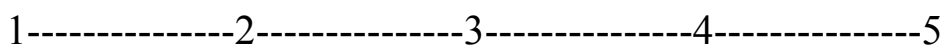

4. If the original meaning of the word "he" was "person," we should continue to use "he" to refer to both males and females today.

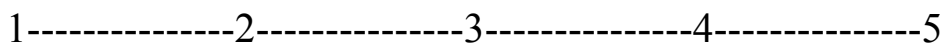
5 . When people use the term "man and wife," the expression is not sexist if the users don't mean it to be. 1 6 . The English language will never be changed because it is too deeply ingrained in the culture.

7. The elimination of sexist language is an important goal. 8. Most publication guidelines require newspaper writers to avoid using ethnic and racial slurs. So, these guidelines should also require writers to avoid sexist language.
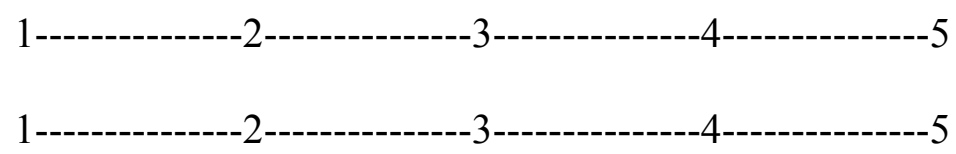
9. Sexist language is related to sexist treatment of people in society. 10. When teachers talk about the history of the United States, they should change expressions, such as "our forefathers," to expressions 
that include women.

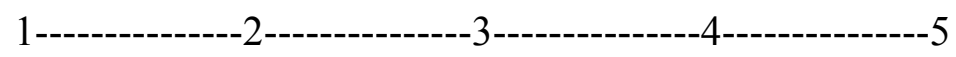

11. Teachers who require students

to use nonsexist language are

unfairly forcing their political

views upon their students.

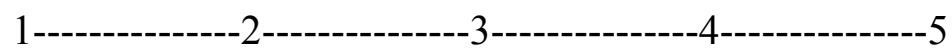

12. Although change is difficult, we still should try to eliminate

sexist language.

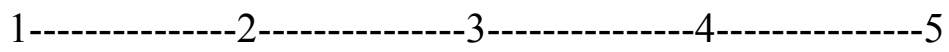

SECTION II: Are the underlined words and phrases in the following sentences sexist?

$1=$ not at all sexist; $2=$ probably not sexist; $3=$ undecided; $4=$ somewhat sexist; $5=$ definitely sexist

13. People should care about all mankind, not just themselves.

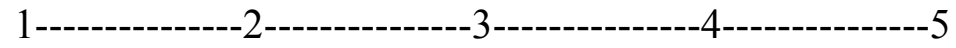

14. The belief that frogs will give you warts is just an old wives' tale.

15. If a child wants to play the piano well, he must practice hard.

$$
1
$$

16. Alice Jones should be chairman

of our committee.

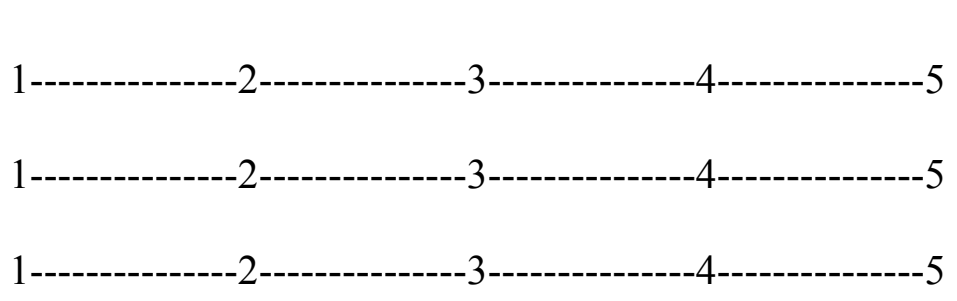

SECTION III: Choose the descriptor that most closely describes you in the following situations. $1=$ very unwilling; $2=$ reluctant; $3=$ undecided; $4=$ somewhat willing; $5=$ very willing

17. When you are referring to a

married woman, how willing are you

to use the title "Ms. Smith"

rather than "Mrs. Smith"?

1-----------------2-----------------3-----------------4-----------------5

18. How willing are you to use the word "server" rather than "waiter" or "waitress"?

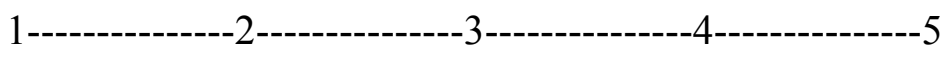

19. How willing are you to use the expression "husband and wife" rather than "man and wife"?

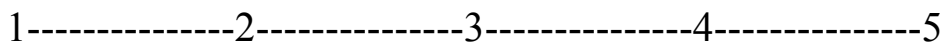

20. How willing are you to use the term "camera operator" rather than "cameraman"?

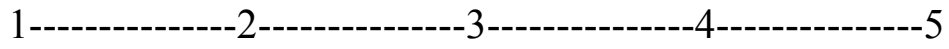

21. How willing are you to use the title "flight attendant" instead of "steward" or "stewardess"?

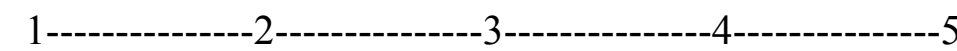

\section{Reminder: Sexist language includes words, phrases, and expressions that unnecessarily differentiate between females and males or exclude, trivialize, or diminish either gender.}




\section{Part 4: Demographics}

Now we would like to ask you some basic questions about yourself.

1. What is your gender?

2. What is your age?

3. What is your highest level of education?

4. Describe your race or ethnic background. 


\section{Condition 4: Female Child/Gender-Inclusive Language}

\section{Part 1: Introduction}

Foster children are defined as individuals under the age of 18 who have been removed from their biological parents, usually as a result of a court order or intervention by local child welfare services, and placed with an individual or family to be cared for. In the state of Illinois, the treatment of foster children by their foster parents is regulated by rules set forth in Title 90.III.e, Part 402, Licensing Standards for Foster Family Homes. We are trying to determine whether the current wording in these rules is clear and understandable enough to guarantee that foster children are kept safe and treated fairly in foster homes.

Imagine you are an individual who has been charged with evaluating allegations of misconduct in the foster care system. In this task, you will read about a situation where foster parents may have broken one or more of the rules governing the treatment of foster children placed in their home. Your job is to interpret the rules given and decide whether the foster parents acted inappropriately. If you decide that a rule was broken, you will then be asked to choose what an appropriate punishment might be for this situation. 


\section{Part 2: Read and Respond}

The following is an example of an event experienced by a foster child. Please read the description carefully and then use it to answer the questions that follow.

Jen is an 11-year-old girl who is currently placed in foster care. She has been living in her current foster home for about 6 months. Jen has a history of behavioral issues, and she often acts out when she does not get her way. The other day, Jen had a tantrum when she was not allowed to watch $\mathrm{TV}$. She began screaming and throwing her possessions around her room. Jen's foster parents pinned her to the floor (i.e., held down her hands and feet) until she calmed down and agreed to sit in time-out.

What is your general impression of Jen? Please provide your answer in the box below using at least 3 sentences.

Do you think Jen was behaving aggressively?

$1-$ No, not at all

2

3

4

5

6

7 - Yes, definitely

The foster parents described in this situation were reported to foster care authorities by a neighbor.

Your job is to decide whether the foster parents broke the foster care rules.

The following excerpt describes some of the rules governing the treatment of children in foster care:

1) Each child shall have the opportunity to learn to assume some responsibility for himself/herself and for household duties in accordance with his/her age, health, and ability. No child shall be permitted to do tasks which are hazardous, dangerous or risk harm to the child.

2) No child shall be subjected to corporal punishment, verbal abuse, threats or derogatory remarks about him/her or his/her family.

3) A child may be temporarily restrained by a person physically holding the child if the child poses a danger to himself/herself or to others. 
4) The personal spending money of a child may be used as a constructive disciplinary measure to teach the child about responsibility and the consequences of his/her behavior. However, no more than $\mathbf{5 0 \%}$ of the child's monthly personal spending money shall be withheld for any reason.

5) All personal or identifying information concerning a foster child, including but not limited to, his/her background, his/her family, and the identity and location of all other persons or families with whom he/she has been, or will be placed, shall be treated as confidential by all persons involved with the child.

Do you think the guidelines described here are directly applicable to what happened to Jen?

$1-$ No, not at all

2

3

4

5

6

7 - Yes, definitely

Based on the guidelines described above, do you think Jen's foster parents are guilty of inappropriate use of discipline?

Yes

No

What type of corrective action do you think Jen's foster parents should receive for this incident? These foster parents did not break any rules; therefore, no corrective action is needed. They should receive only a verbal warning. They should receive a written warning that is placed on their permanent record.

— They should receive a written warning AND undergo more training about how to appropriately discipline foster children.

They should receive a written warning, undergo more training, AND the child should be removed from their home.

- They should lose their foster care license.

— They should lose their foster care license AND be charged with child abuse.

_ Other, please specify:

Any additional comments about this scenario (optional): 


\section{Part 3: Attitudes Toward Sexist/Nonsexist Language Questionnaire}

We would like to ask you a few questions about how you interpret different types of language.

Please use the following definition in completing this questionnaire: Sexist language includes words, phrases, and expressions that unnecessarily differentiate between females and males or exclude, trivialize, or diminish either gender.

SECTION I: For each of the following expressions, choose the descriptor that most closely corresponds with your beliefs about language.

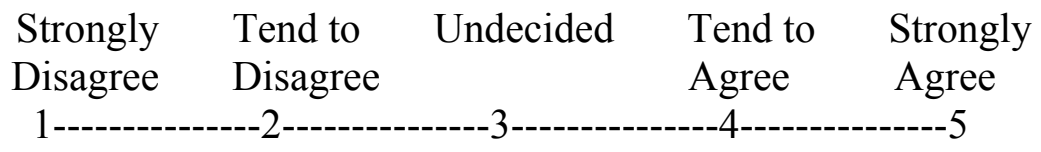

1. Women who think that being called a "chairman" is sexist are misinterpreting the word "chairman."

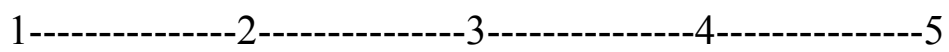

2. We should not change the way the English language has traditionally been written and spoken.

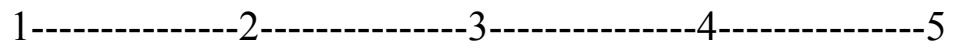

3. Worrying about sexist language is a trivial activity.

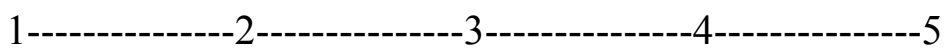

4. If the original meaning of the word "he" was "person," we should continue to use "he" to refer to both males and females today.

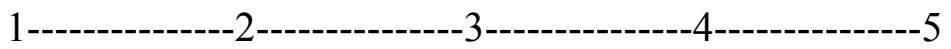
5 . When people use the term "man and wife," the expression is not sexist if the users don't mean it to be. 1 6 . The English language will never be changed because it is too deeply ingrained in the culture.

7. The elimination of sexist language is an important goal. 8. Most publication guidelines require newspaper writers to avoid using ethnic and racial slurs. So, these guidelines should also require writers to avoid sexist language.
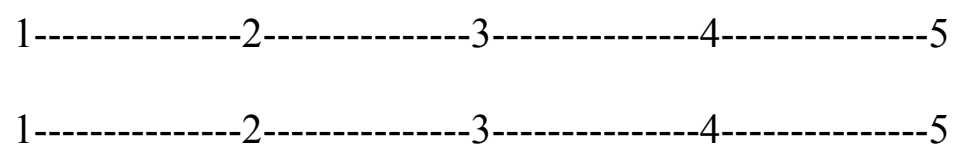
9. Sexist language is related to sexist treatment of people in society. 10. When teachers talk about the history of the United States, they should change expressions, such as "our forefathers," to expressions 
that include women.

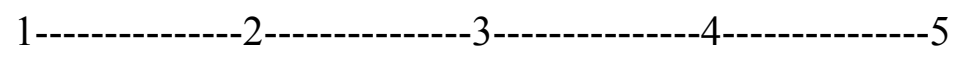

11. Teachers who require students

to use nonsexist language are

unfairly forcing their political

views upon their students.

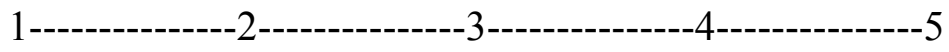

12. Although change is difficult, we still should try to eliminate

sexist language.

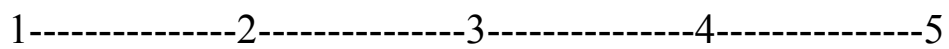

SECTION II: Are the underlined words and phrases in the following sentences sexist?

$1=$ not at all sexist; $2=$ probably not sexist; $3=$ undecided; $4=$ somewhat sexist; $5=$ definitely sexist

13. People should care about all mankind, not just themselves.

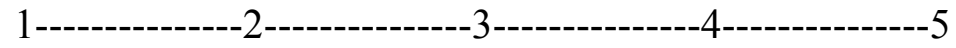

14. The belief that frogs will give you warts is just an old wives' tale.

15. If a child wants to play the piano well, he must practice hard.

$$
1
$$

16. Alice Jones should be chairman

of our committee.

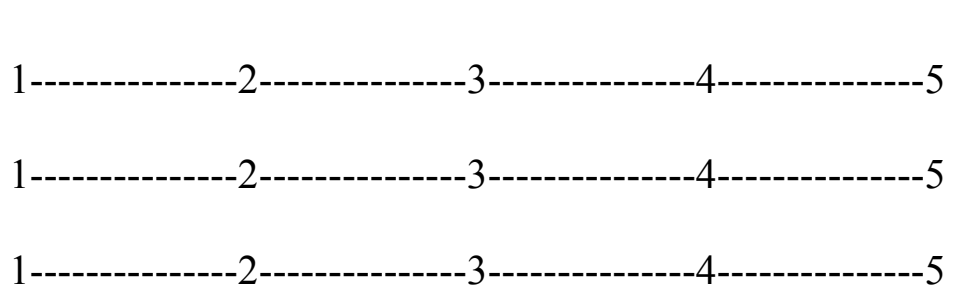

SECTION III: Choose the descriptor that most closely describes you in the following situations. $1=$ very unwilling; $2=$ reluctant; $3=$ undecided; $4=$ somewhat willing; $5=$ very willing

17. When you are referring to a

married woman, how willing are you

to use the title "Ms. Smith"

rather than "Mrs. Smith"?

1-----------------2-----------------3-----------------4-----------------5

18. How willing are you to use the word "server" rather than "waiter" or "waitress"?

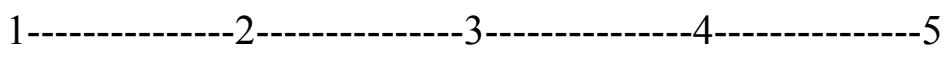

19. How willing are you to use the expression "husband and wife" rather than "man and wife"?

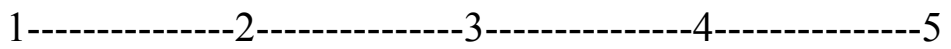

20. How willing are you to use the term "camera operator" rather than "cameraman"?

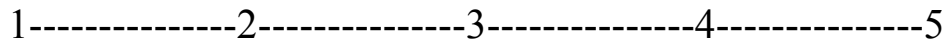

21. How willing are you to use the title "flight attendant" instead of "steward" or "stewardess"?

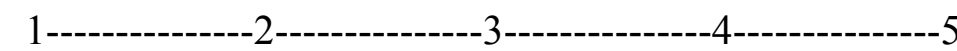

\section{Reminder: Sexist language includes words, phrases, and expressions that unnecessarily differentiate between females and males or exclude, trivialize, or diminish either gender.}




\section{Part 4: Demographics}

Now we would like to ask you some basic questions about yourself.

1. What is your gender?

2. What is your age?

3. What is your highest level of education?

4. Describe your race or ethnic background. 


\section{APPENDIX B: INFORMED CONSENT AND DEBRIEFING INFORMATION}

Informed Consent

PLEASE READ THIS DOCUMENT CAREFULLY. CLICK TO CONTINUE BELOW ONLY IF YOU AGREE TO PARTICIPATE AND YOU FULLY UNDERSTAND YOUR RIGHTS. YOU MUST BE 18 YEARS OF AGE TO GIVE YOUR CONSENT TO PARTICIPATE IN RESEARCH. FOR THIS PROJECT, YOU MUST BE 18 YEARS OF AGE TO PARTICIPATE. IF YOU DESIRE A COPY OF THIS CONSENT FORM, YOU MAY PRINT THIS FORM.

The policy of the Department of Psychology at Illinois State University is that all research participation in the Department is voluntary, and you have the right to withdraw at any time, without prejudice, should you object to the nature of the research. Your responses are confidential. Any report of the data collected will be in summary form, without identifying individuals. You are entitled to ask questions and to receive an explanation after your participation.

If you have concerns about your participation in this study, you may contact:

Dr. John B. Pryor Email: pryor@ilstu.edu

Description of the Study:

This is a 1 session study in which a number of different kinds of measures are being evaluated.

In participating, we will ask you to do the following:

- One task is to read a section of legal language concerning the treatment of foster children in Illinois.

- Another task is to visualize what you think of as a "typical" foster child and choose some traits to describe the child.

- The third is to read about a hypothetical situation involving foster care and answer some questions about whether you believe certain rules were followed.

- Answer some basic demographic information questions about yourself. 


\section{Nature of Participation:}

You should be able to complete this survey in about 10 minutes or less.

\section{Purpose of the Study:}

The purpose of this study is to determine the effectiveness of current legal language in protecting children from exploitation, neglect, and abuse while in foster care.

\section{Possible Risks:}

a) You will be asked how you feel about a hypothetical situation. You will also be asked to read about the treatment of foster children in Illinois. Either of these tasks might make you slightly uncomfortable.

b) Any information about yourself will not be used to identify you in any way. All information collected will remain completely confidential. Any online survey has the potential of identifying the IP Address of the computer used to complete the survey. However, we promise to destroy any digital connections that exist between your IP address and your answers to our survey and will not attempt to learn your identity in any way.

\section{Possible Benefits:}

By choosing to participate in this research, you will be contributing to the furthering of psychological science. By choosing to participate in this research, you may gain some insights into your own thought processes and those of others. You may also learn more about the foster care process.

\section{Compensation for your time:}

a) As a token of appreciation, and to compensate you for the time you spend on the questionnaires, you will be given $\$ 0.25$. This money will be paid to you through the AMAZON MTurk service. 
b) When your participation is complete, you will be given a completion code number. You can then return to the MTurk page that directed you here and enter that code in the blank provided.

\section{Confidentiality:}

Participation in this research is confidential. You will be assigned a participant code number, and any information about your identity will be removed from your data records. All data will be kept in secure files. Electronic data will be stored in accordance with the standards of Illinois State University, federal regulations and the American Psychological Association. Electronic data will be kept confidential and will be destroyed when it is no longer useful. No one will be able to know which are your questionnaire responses. Finally, remember that we are not interested in the responses of a particular individual; we are studying the usefulness of the tests in question for people in general.

\section{Opportunities to Question:}

Any technical questions about this research may be directed to the Principal Investigator, Dr.

John B. Pryor, Professor of Psychology, pryor@ilstu.edu

\section{Opportunities to Withdraw at Will:}

If you decide now or at any point to withdraw this consent or stop participating, you are free to do so at no penalty to yourself. You are free to skip specific questions and continue participating at no penalty.

\section{Opportunities to be Informed of Results:}

In all likelihood, the results will be fully available around: June 2016. Preliminary results will be available earlier. If you wish to be told the results of this research, please contact:

Principal Investigator: Dr. John B. Pryor, pryor@ilstu.edu

There is a chance that the results from this study will be published in a scientific Psychology 
journal, which would be available in many libraries. In such an article, participants would not be identified as individuals in any way.

I voluntarily agree to participate in this survey. I further acknowledge that I can print a copy of this consent form for my records if I so desire.

(By clicking yes, you are also stating that you are 18 years of age or older.)

PRESS "YES" TO DEPLOY SURVEY LINK

Yes

No (I am not 18 or I choose not to participate) 


\section{Debriefing Information}

Thank you participating in this study! The advancement of psychological science is only possible because of people like you who take the time to volunteer to participate in empirical research studies. The purpose of this study is to examine the effects of biased language on interpretations of legal standards and, consequently, the treatment of individuals affected by those standards. During the first phase of the experiment, participants were assigned to one of four experimental conditions. These conditions varied the content of the foster care rulings that you read specifically, they varied whether a generic child was referred to as he or more inclusively as he/she. The conditions also varied whether the child described in the hypothetical scenario was a boy or girl. In past research, varying the type of pronouns used, along with the gender of the person mentioned, has influenced individuals' interpretations and subsequent judgments of various texts. We plan to examine whether the wording variations used in this study had a similar impact. Research like this helps us to understand how the wording of legal language can affect the treatment of vulnerable populations such as foster children.

This study is not interested in the responses of specific people; we are attempting to learn about groups, not individuals. As a reminder, your data will be assigned a code to guarantee confidentiality, and no identifying information will be kept or reported. If you have any questions, please contact Dr. John B. Pryor, the Principal Investigator, at pryor@ilstu.edu. If you are interested in the results of the study, they will more than likely be available towards the end of May 2016. Once again, thank you for your participation! 